\title{
Modelling of solar thermochemical reaction systems
}

\author{
Vincent M. Wheeler ${ }^{\mathrm{a}}$, Roman Bader ${ }^{\mathrm{a}}$, Peter B. Kreider ${ }^{\mathrm{a}}$, Morteza Hangi ${ }^{\mathrm{a}}$, Sophia Haussener ${ }^{\mathrm{b}}$, \\ Wojciech Lipiński ${ }^{\text {a,* }}$
}

${ }^{a}$ Research School of Engineering, The Australian National University, Acton ACT 2601, Australia

${ }^{\mathrm{b}}$ Institute of Mechanical Engineering, EPFL, 1015 Lausanne, Switzerland

\section{A R T I C L E I N F O}

\section{Article history:}

Received 24 March 2017

Received in revised form 18 July 2017

Accepted 25 July 2017

Available online xxxx

\section{Keywords:}

Thermochemical

Modelling

Computational

High-temperature

Transport

Reactor

\begin{abstract}
A B S T R A C T
This article reviews the progress, challenges and opportunities in numerical modelling of thermal transport, thermochemical reactions and thermomechanics in high-temperature solar thermochemical systems. Continuum-scale models are presented in mathematical detail while highlighting the literature that uses them. The discussion is enhanced by selected examples of numerical studies of solar thermochemical systems for solar fuels and commodity material production. Property predictions necessary for the modelling of solar thermochemical reaction systems are covered.
\end{abstract}

(c) 2017 Elsevier Ltd. All rights reserved.

\section{Introduction}

Thermochemical reaction systems driven by concentrated solar irradiation hold great potential as environmentally benign alternatives to traditionally fossil-fuel-intensive industrial processes, including the production of transportation and stationaryapplication fuels as well as material commodities such as lime, metals, and ammonia (Bader and Lipiński, 2016a; Romero and Steinfeld, 2012). Solar thermochemical applications usually target highly endothermic, large-scale processes that require hightemperatures to proceed spontaneously (Bader and Lipiński, 2016b). Point-focusing solar concentrators can provide heat for the required high-temperatures. However, the long-term operation of processes at temperatures beyond the operating temperature limits of steel-based components remains a technical challenge. In hybrid processes, the high temperature requirements are alleviated with the aid of an electric energy input or a reaction agent, although usually at the expense of added process complexity, costs, or $\mathrm{CO}_{2}$ emissions. There are also many industrial processes that can be supplemented with solar energy as a generic source of dispatchable process heat. Solar thermochemical processes can be grouped according to the feedstocks and energy sources used: solar-thermal $\mathrm{H}_{2} \mathrm{O} / \mathrm{CO}_{2}$ splitting processes; hybrid (solar-

\footnotetext{
* Corresponding author.

E-mail address: wojciech.lipinski@anu.edu.au (W. Lipiński).
}

electrothermal or solar-carbothermal) processes; and processes for the solar-thermal conversion, upgrade, and de-carbonisation of carbonaceous feedstocks (e.g. coal, natural gas, biomass). Solar thermochemical fuel production processes generally aim at producing synthesis gas $\left(\mathrm{CO}\right.$ and $\left.\mathrm{H}_{2}\right)$, which can be further processed to conventional liquid fuels (e.g. diesel, kerosene, ethanol, dimethyl ether). Material and commodity related processes can be further grouped per the process type: production of lime for the cement industry; production of ammonia as a fertiliser or energy carrier; production of metals, metal oxides, carbides, and nitrides from ore or from waste materials for manufacturing; capture of $\mathrm{CO}_{2}$ from flue gases or from the atmosphere to mitigate climate change and as a feedstock to produce carbon-neutral fuels; and conversion of bulk materials into nanostructures used as advanced materials. A recent comprehensive review and discussion of solar thermochemical processes can be found in (Bader and Lipiński, 2016a).

Introducing high-flux solar heat into high-temperature industrial processes in a controlled, efficient, and non-destructive way poses a thermal engineering challenge. Computational models can be powerful tools to evaluate and optimise the design and performance of solar thermochemical reaction systems (STRSs) and guide the engineering process, thus reducing the need for costly and time-consuming repetitive prototype development and experimental testing. However, computational modelling of STRSs can be challenging. First, these systems typically utilise solid-gas heterogeneous media at temperatures ranging from several hundred to more than $2000^{\circ} \mathrm{C}$. Second, the full engineering scope of 


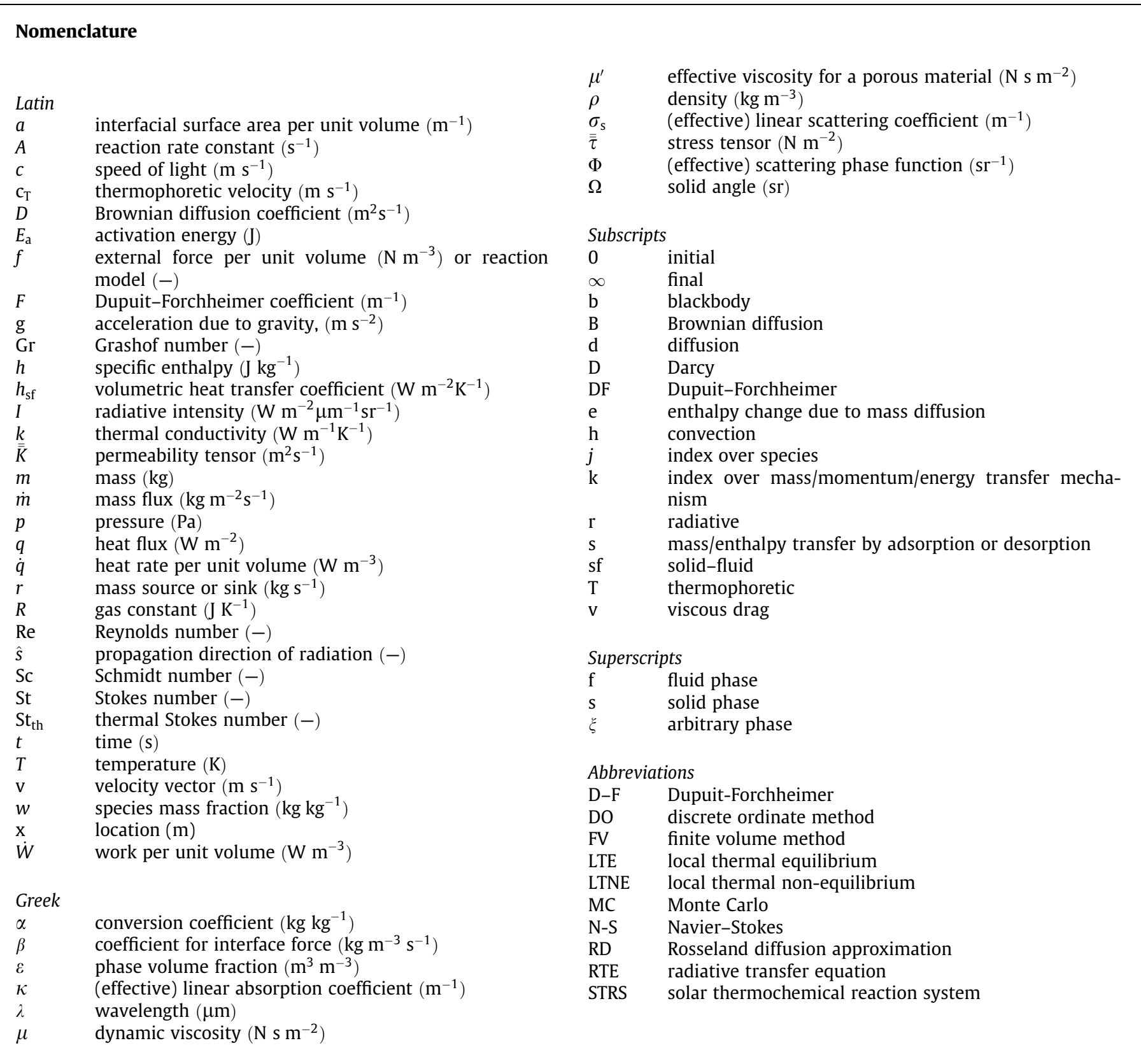

STRSs includes considerations that span kilometres-such as power grid integration, optical concentrator field design, and plant process design-down to the scale of nanometres when considering the chemical and morphological design of the reactive materials. Third, conditions in and around STRSs fluctuate due to many time-dependent phenomena ranging from seasonal solar flux variations to rapid chemical kinetics occurring on microsecond time scales. Finally, STRSs are generally highly multi-physical; radiative, conductive, and convective heat transfer, momentum transfer, and complex mass transfer involving multiple phases, species, and chemical reactions all play key roles in the operation of reactor systems. In addition, thermally induced mechanical stresses are often critical. Such high temperatures, variations in length scales, temporal scales and physical complexity represent significant challenges when numerically modelling STRSs. A recent perspective by Floudas et al. (2016) highlights the challenges of multi-scale phenomena for the energy sector as a whole.
In this review, we will focus on the numerical modelling of the complex thermophysical phenomena occurring inside STRSs. Important features that require modelling attention include: $(i)$ chemically reacting solid-gas interfaces, (ii) multi-component, often multiphase, mass transport, (iii) high-flux solar irradiation and its interaction with complex reacting media at high temperatures and $(i v)$ the transient nature of solar energy leading to a time-varying process heat input to the STRS. Items (i) and (ii) together constitute a "classical" chemical reactor system where the dominant heat transfer mechanisms are conduction and/or convection. The tome by Jakobsen (2014) is an excellent resource for modelling considerations in these areas. The addition of highly directional, transient, intense irradiation is the defining feature of STRSs. Interactions between thermal radiation and active materials are of keen interest since the conversion of incident solar irradiation to the creation or destruction of chemical bonds is the fundamental process that defines the efficiency of STRSs. Characterisation and simulation techniques that accurately, but 
economically, account for these challenges are required to enable the model-based design of efficient reactor components and systems by advancing the understanding of the complex thermophysical transport processes taking place within them.

This paper aims to provide a review of the research area of numerical modelling of STRSs, outline the challenges unique to high-temperature STRS modelling, highlight the existing literature in the field and their attempts to overcome these hurdles, and guide the reader to relevant studies related to different material/chemical processes and physical reactor configurations. The reader is also referred to the recent reviews of the areas of heat transfer within STRSs and experimental studies of them by Lipiński et al. (2013) and Alonso and Romero (2015), respectively. Fig. 1 provides a graphic representing the scope of this review. Particular attention will be paid to the macroscopic models that are used to optimise the thermal performance of proposed STRS designs. These models will be covered in mathematical detail while also pointing to relevant literature and providing examples in Section 2. Section 3 provides a survey of the important thermal transport, thermodynamic, and chemical properties that must be well-characterised to carry out a meaningful STRS simulation that facilitates engineering design. A summary and future perspectives are given in Section 4.

\section{Continuum modelling of thermochemical transport}

The quality of any physical model is a subjective topic. The aims of a simplified one-dimensional model meant to drive a control algorithm for a dilute particle reactor, e.g. (Saade et al., 2012), or a three-dimensional model to refine the design and operation of a novel rotating porous material reactor design, e.g. (Lapp et al., 2013), are very different. However, the physical processes existing in the STRSs share many attributes and their mathematical descriptions are based on the same principles. We will use these principles-namely conservation of momentum, mass, and energy-to guide our discussion of modelling approaches and the literature. The treatment of thermal radiation is sufficiently important to warrant a section on its own. Models discussed here vary in complexity and purpose, from those elucidating the effects of radiation-chemistry coupling in simplified one-dimensional geometries and neglecting other thermal transport processes to broader

\section{Modelling and simulation}

\section{Discrete scale}

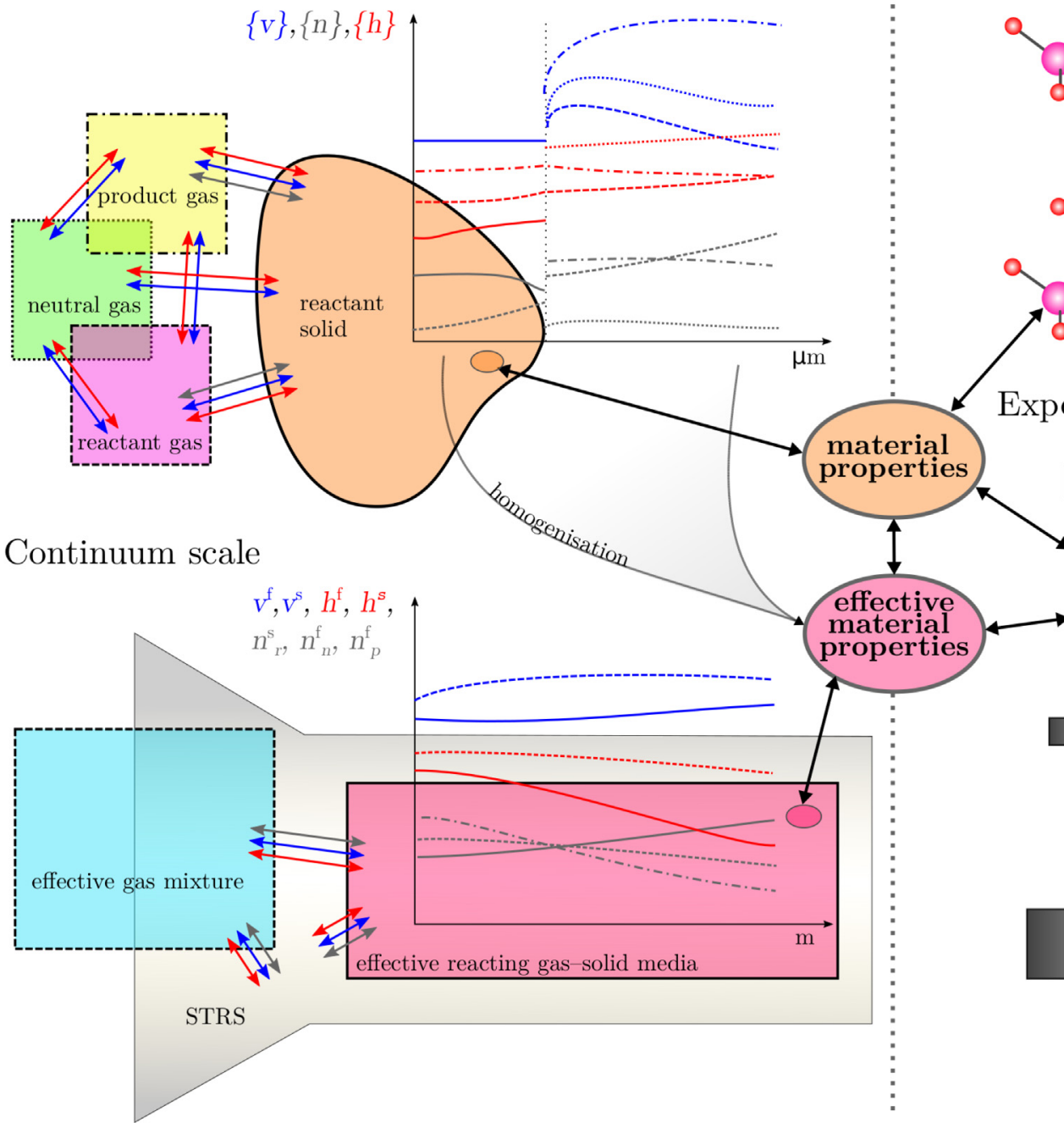

\section{Properties determination} Ab initio calculations

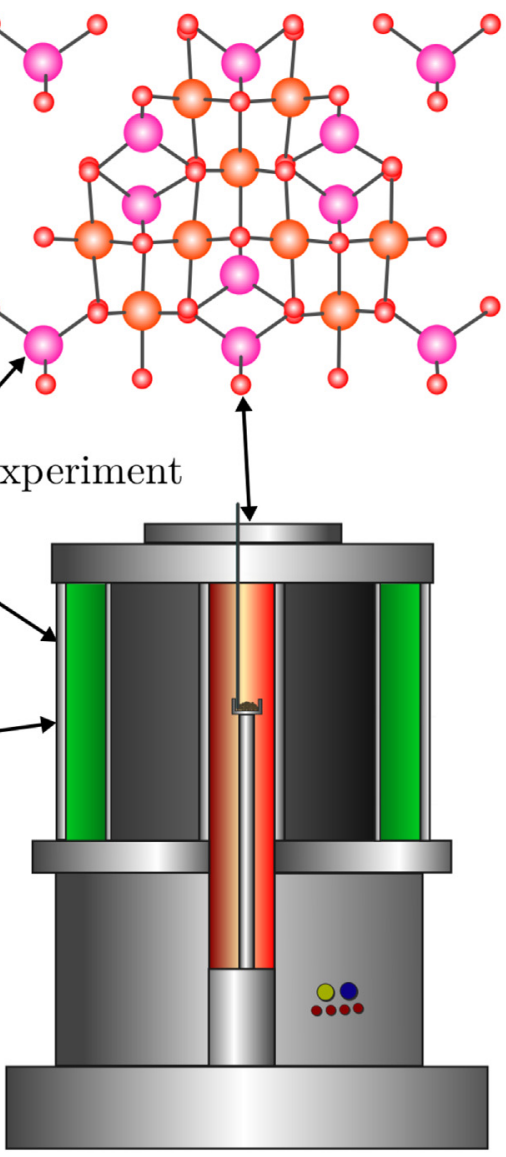

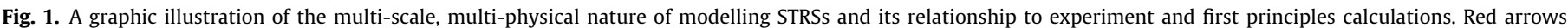

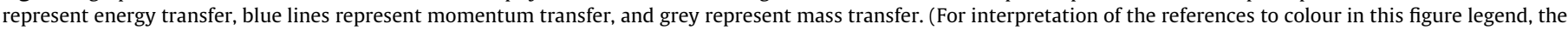
reader is referred to the web version of this article.) 
approaches involving combined heat and mass transfer in geometries representative of actual STRSs. Fig. 1 gives an illustration of the multi-scale and multi-physical nature of STRS modelling and its connections to theory and experiments.

Since STRSs usually involve different types of solid-gas, twophase systems, the type of fluid-mechanical interactions the active material has with itself, i.e. the type of or lack of fluidisation is how we will divide the different types of STRSs. Such interactions have a very strong influence on the performance, modelling, and operating conditions of the reactor. The widely-referenced works of Levenspiel on reactor engineering (Levenspiel, 1999) and fluidisation (Kunii and Levenspiel, 1992) offer four or five different regimes depending on the relative gas velocity and density of the active material. In our discussion, we will use three regimes because the modelling choices are generally consistent within them: (i) dilute fluidised-reacting particles are suspended or fluidised and make up a very small fraction of the reactor volume such that they can be assumed to not interact with each other, (ii) dense fluidised-reacting particles may make up much of the reactor volume and are dynamically moving and interacting with each other, (iii) stationary-the active solid material does not move, e.g. porous materials, solid materials, and packed beds of particles. Researchers have focused their energies on the two extreme operating conditions-dilute fluidised and stationary. This is perhaps not surprising given the extra difficulty found in modelling the detailed mechanical interactions of dense fluidised beds as will be discussed further below. These regimes also have some distinct advantages. Very small particles have the potential to be very efficient radiation absorbers with absorption efficiencies that, unlike materials with larger features, can be greater than one (Bohren and Huffman, 2004). Thus, for a material to absorb very well relative to its size-the trait needed to achieve high temperature within a particle with relatively little input-tiny particles offer a distinct advantage. However, problems with fluidisation, low solid-to-gas mass ratios, and high convective heat transfer can make them difficult to use in engineering applications. Porous materials and packed beds offer simplicity in material handling within a STRS, but suffer from large pressure drops through the reactive material causing higher pumping requirements. They are also generally more optically dense leading to difficulty in uniformly heating the reactive material via radiative heat transfer.

The disparate length scales existing in STRSs bring about challenges to the modelling of the thermophysical processes occurring within them. For our purposes, we will define two length scales: ( $i$ ) discrete scale-the scale at which detailed geometric features are fully resolved, often reaching characteristic lengths on the order of nanometres, and (ii) continuous scale-the scale at which detailed geometry must be approximated in order to make the modelling of macroscopic phenomena possible. The continuous scale is often the scale of the STRSs themselves with characteristic lengths on the order of centimetres to metres, although the methods used to describe transport at this scale have also been used to describe transport in small reactor components such as reacting irradiated particles (Yue and Lipiński, 2015c). The mathematical description of discrete scale phenomena in STRSs-fluid mechanics, heat transfer, mass transfer, transport of radiation-are generally wellknown and treatments may be found in dozens of textbooks; a general knowledge of them is assumed in this review. The continuous scale models that are widely used to describe macroscopic transport are generally resultant from a process of homogenisation, a powerful way to deal with the tremendously different length and temporal scales that often exist in STRSs.

Homogenisation methods provide a way of rigorously averaging the behaviour of physical systems at the small scale such that the macroscopic behaviour is retained, i.e. obtain continuous-scale governing equations. This process also goes by the names "coarse-graining”, or just "averaging." Without homogenisation, we are forced to resolve the local boundaries between different fluids and solids using interface relations of mass, momentum, and energy in the discrete scale as shown in Fig. 1. This is often an intractable undertaking due to computational expense and complexity. There are numerous methodologies for rigorous homogenisation in space, time, or space and time simultaneously using an ensemble approach as admirably outlined by Jakobsen (2014). Even simple mixing rules, such as a weighted average of specific heat capacities for a two-component gas, constitute a homogenisation whether it is rigorously established or accepted by convention. Ultimately, a set of homogenised equations governing momentum, energy, and mass transfer are obtained that can be solved at the reactor scale. A formal homogenisation of the radiative transfer equation for its solution in multi-component media was only recently put on a solid footing by use of volume averaging theory (Lipiński et al., 2010a,b; Petrasch et al., 2011) although its use in reactor modelling is yet to appear. Homogenised equations require auxiliary closure relations in order to solve them. Pertinent examples include the Dupuit-Forchheimer coefficient and the volumetric convective heat transfer coefficient used in porous media flow. Additionally, values for effective transport properties such as effective thermal conductivities are necessary.

Formal statements of the homogenised conservation laws and the terms appearing in them will follow. First, we pause here and introduce some notational conventions to help clarify the subsequent discussion. Homogenisation procedures result in spatially and/or temporally averaged quantities on the macroscopic scale. Although many authors choose to denote averaged quantities with a symbol such as angled brackets, i.e. $\langle\cdot\rangle$, we will provide no such notation, and quantities can be assumed to represent an average. Superscripts will represent the phase of the material being described, "s" for solid and " $\mathrm{f}$ " for fluid. When the equation holds for either phase a " $\xi$ " will appear. Italic subscripts will denote a particular species and upright subscripts will denote a particular phenomenon, for example "d" for diffusion.

\subsection{Mass transfer}

Enforcing mass conservation within STRSs requires accounting for multiple species and phases where the species may be created or destroyed by chemical processes. For a particular phase and species, it can be stated as

$\frac{\partial}{\partial t}\left(\varepsilon^{\xi} \rho^{\xi} w_{j}^{\xi}\right)+\nabla \cdot\left(\varepsilon^{\xi} \rho^{\xi} \mathbf{v}^{\xi} w_{j}^{\xi}\right)=\sum_{\mathrm{k}} r_{\mathrm{k} j}^{\xi}$

where $\varepsilon$ is the volume fraction of the phase, $\rho$ is the mixture density, $\mathbf{v}$ is the velocity vector, $w$ is the mass fraction of the species, $j$ denotes the species. On the right hand side of (1), $r_{\mathrm{k}}$ denotes a mass source or sink describing chemical reactions to or from the species under consideration as well as any other process by which the $j$-th species enters or exits the local control volume that is not accounted for in the left-hand-side advection term. Often Eq. (1) is solved for each species along with an overall mass conservation equation-the sum over all components $j$ in Eq. (1)-in order to determine the phase mixture density.

Relevant mass transfer processes include advection, diffusion, chemical reaction, and sorption. The advection term in Eq. (1) appears whenever a momentum equation is solved to get a velocity field in the solution domain (see Section 2.2). Diffusion of individual gas species is often included in modelling studies as represented by,

$r_{\mathrm{B}}^{\mathrm{f}}=\nabla \cdot\left(\rho^{\mathrm{f}} D^{\mathrm{f}} \nabla w^{\mathrm{f}}\right)$,

where $D$ is the Brownian diffusion coefficient. 
Reaction rate terms that appear as a source or sink in the species conservation equations, denoted here generically by $r_{\mathrm{r} j}^{\xi}=r_{\mathrm{rj}}^{\xi}\left(\varepsilon^{\xi}, \rho^{\xi}, w_{i}^{\xi}, T\right)$, introduce the need for experimental data or reaction rate models to characterise them. This term is of paramount importance to the accurate modelling of an STRS and we will withhold further discussion until Section 3.2 where we discuss the determination of reaction rates and the underlying phenomena in general. The availability of kinetic rate data and models depends on the active materials and how well-studied they are. Experimentally determined rates have been found and used in STRS modelling studies utilising numerous reactive materials as summarised in Table 1.

Mass transfer between the active solid material and the surrounding gas may add additional complications to simulation studies, particularly when the solid-gas reactions occur within the volume of the solid whose mass is not negligibly small as with dense fluidised and stationary systems. Keene et al. derives an expression for adsorption and desorption of oxygen into and out of partially reduced porous ceria structures in terms of the local temperature, oxygen partial pressure, and non-stoichiometry (Keene et al., 2013). It appears in a general form as

$r_{s}^{\xi}= \pm \sum_{j} \dot{m}_{j}^{\mathrm{f}} a$

where $\dot{m}$ is a mass flux across a solid-gas interface with interfacial surface are per volume $a$ and the sign depends upon whether the gas is entering or exiting the solid. The expression was further used in the work of Bala Chandran et al. (2015a). Oles and Jackson (2015) included a rather detailed description of mass transfer in an irradiated particle curtain by including gas diffusion and sorption by considering the particle composition in the bulk, sub-surface, and surface. von Zedtwitz and Steinfeld (2005) and von Zedtwitz et al.
(2007) considered similar mechanisms when studying the steam gasification of coal in a dense fluidised bed. Ströhle et al. (2014) considered gas transfer to and from porous particles undergoing calcium oxide/hydroxide cycling and go a step further by solving a full species diffusion equation within the individual granules of a packed bed.

In dilute systems with very small particles, behaviours that require special care when enforcing conservation of mass are Brownian diffusion (for low Schmidt numbers) and thermophoretic diffusion of the solid particles, in addition to advection driven by the surrounding gases, as was considered in Martinek et al. (2012a,b). Brownian particle diffusion was also considered in (Perkins and Weimer, 2007). These phenomena are described by

$r_{\mathrm{B}}^{\mathrm{s}}=\nabla \cdot\left(\rho^{\mathrm{s}} D^{\mathrm{s}} \nabla w^{s}\right)$,

and

$r_{\mathrm{T}}^{\mathrm{s}}=-\nabla \cdot\left(\rho^{\mathrm{s}} \mathbf{c}_{\mathrm{T}} w^{\mathrm{s}}\right)$

respectively. Here $\mathbf{c}_{\mathrm{T}}$ is the thermophoretic velocity which is in general a function of the local density, temperature, and temperature gradient (Hinds, 2012).

Reactor designs that include an ablated material at a macroscopic scale-as in the $\mathrm{ZnO} / \mathrm{Zn}$ cycle-must deal with the problem of shrinking solid masses that leads to dynamically changing domain size or particle size. Scattering and absorption behaviour of radiation in participating media is particularly strongly influenced by changing particle size. Studies dealing with this phenomenon include (Schunk et al., 2009a, 2009b; Villafán-Vidales et al., 2015) for dense, large ZnO samples, (Dombrovsky et al., 2009; Kenarsari and Zheng, 2014) for ZnO and coal particles and (Kenarsari and Zheng, 2014; Lipiński and Steinfeld, 2005; Lipiński

Table 1

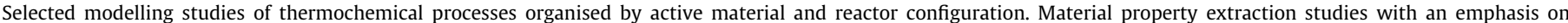

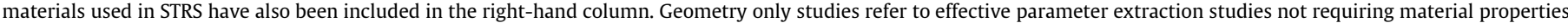

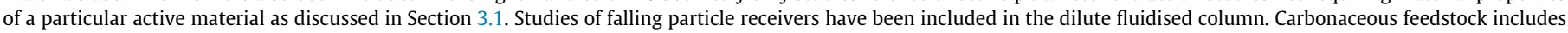

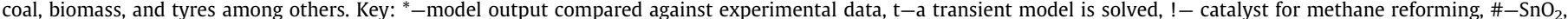
f-ferrites, $\mathrm{r}-\mathrm{Rh}$-coated $\mathrm{SiC}$, @-mixture of $\mathrm{SiO}_{2}, \mathrm{ZnO}$, and $\mathrm{C}$ particles.

\begin{tabular}{|c|c|c|c|c|}
\hline & Dilute fluidised reactor & Dense fluidised reactor & Stationary reactor & Material study \\
\hline $\mathrm{CeO}_{2}$ & (Oles and Jackson, 2015) & (Groehn et al., 2016) & $\begin{array}{l}\text { (Bader et al., 2015; Bala Chandran } \\
\text { et al., 2015b) (Bala Chandran et al., } \\
\text { 2015a; Keene et al., 2013, 2014; } \\
\text { Lapp et al., 2013; Lapp and } \\
\text { Lipiński, 2014) }\end{array}$ & $\begin{array}{l}\text { (Wheeler et al., 2014) (Randrianalisoa } \\
\text { and Lipiński, 2014) (Suter et al., 2014) } \\
\text { (Dombrovsky et al., 2012; Ganesan } \\
\text { et al., 2013a,b),, (Haussener and } \\
\text { Steinfeld, 2012), (Ackermann et al., } \\
\text { 2014, } 2017\end{array}$ \\
\hline $\mathrm{ZnO} / \mathrm{Zn}$ & 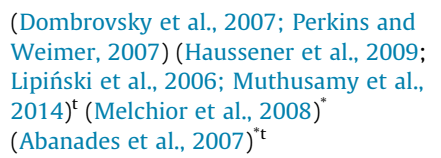 & & $\begin{array}{l}\text { (Villafán-Vidales et al., 2012) } \\
\text { (Dombrovsky et al., 2009; Müller } \\
\text { et al., 2008; Schunk et al., 2009a; } \\
\text { Villafán-Vidales et al., 2015) }{ }^{* t}\end{array}$ & $\begin{array}{l}\text { (Coray et al., 2009; Schunk et al., } \\
\text { 2009b) }\end{array}$ \\
\hline $\begin{array}{l}\text { Calcium } \\
\text { carbonate, } \\
\text { Calcium } \\
\text { oxide }\end{array}$ & & & $\begin{array}{l}\text { (Lipiński and Steinfeld, 2004; } \\
\text { Ströhle et al., 2014)"t }\end{array}$ & $\begin{array}{l}\text { (Ebner and Lipiński, 2012; 2011; Yue } \\
\text { and Lipiński, 2015a,b,c; Dombrovsky } \\
\text { and Lipiński, 2007) (Akolkar and } \\
\text { Petrasch, 2011; S. Haussener et al., } \\
\text { 2010a) }\end{array}$ \\
\hline $\begin{array}{l}\text { Carbonaceous } \\
\text { feedstock }\end{array}$ & $\begin{array}{l}\text { (Lipiński and Steinfeld, 2005; Martinek } \\
\text { and Weimer, 2013a) (Martinek et al., } \\
\text { 2012a; Saade et al., 2012; Z'Graggen } \\
\text { and Steinfeld, 2009; 2008) (Lipiński } \\
\text { et al., 2005) }{ }^{*} \text { t }\end{array}$ & $\begin{array}{l}\text { (Kenarsari and Zheng, } \\
\text { 2014; Zedtwitz et al., } \\
\text { 2007; Zedtwitz and } \\
\text { Steinfeld, 2005) } \text { (Gordillo }^{*} \\
\text { and Belghit, 2011a) }{ }^{*} \mathrm{t}\end{array}$ & $\begin{array}{l}\text { (Melchior et al., 2009)* (Gordillo } \\
\text { and Belghit, 2011b; Piatkowski } \\
\text { and Steinfeld, 2008) }{ }^{*}{ }^{*}\end{array}$ & (Haussener et al., 2012; 2010b) \\
\hline $\begin{array}{l}\text { Geometry } \\
\text { only }\end{array}$ & & & & $\begin{array}{l}\text { (Akolkar and Petrasch, 2012; 2011; Jörg } \\
\text { Petrasch, Meier, et al., 2008; Petrasch } \\
\text { et al., 2007) }\end{array}$ \\
\hline Other & & & $\begin{array}{l}\text { (Lu et al., 2016)*! (Villafán-Vidales } \\
\text { et al., 2012)\# (Martinek et al., } \\
\text { 2014) } \text { (Villafán-Vidales et al., }^{\text {f }} \text { (2011) }{ }^{* \text { f }} \text { (Wang et al., 2014a,b)! }\end{array}$ & $\begin{array}{l}\text { (Jörg Petrasch, Schrader, et al., 2008) } \\
\text { (Jäger et al., 2009) }\end{array}$ \\
\hline
\end{tabular}


et al., 2005; Piatkowski and Steinfeld, 2008) for packed beds of coal.

\subsection{Momentum transfer}

Accurately describing the mechanical interaction between multi-component gas flows and the reacting materials is one of the biggest difficulties in modelling high temperature STRSs. A general conservation of momentum statement can be rigorously stated for the fluid of a solid-gas system after a proper homogenisation method as

$$
\frac{\partial}{\partial t}\left(\varepsilon^{\xi} \rho^{\xi} \mathbf{v}^{\xi}\right)+\nabla \cdot\left(\varepsilon^{\xi} \rho^{\xi} \mathbf{v}^{\xi} \mathbf{v}^{\xi}\right)=\nabla \cdot \bar{\tau}^{\xi}+\sum_{\mathrm{k}} \mathbf{f}_{k}^{\xi},
$$

where $\rho$ is density, $\mathbf{v}$ is the velocity vector, $\overline{\bar{\tau}}$ is the stress tensor, $\mathbf{f}_{\mathrm{k}}$ denotes an external force per volume, and $t$ is time. The appearance of two vectors side by side denotes an outer product. The summation symbol on the external force term allows for many external forces to be acting on some volume in space. A typical example would be gravity, $\mathbf{f}_{\mathrm{g}}^{\mathrm{f}}=\rho^{\mathrm{f}} \mathbf{g}$, but many other contributions are concei vable-particularly when considering a dense fluidised or stationary system as will be discussed below. The stress tensor term needs to be approximated by some constitutive relationship between the stress and the velocity field in order to close the model. We will focus here on the fluid phase where this term is always important and appears in much of the surveyed literature.

The momentum conservation of gasses in these systems is often well-represented with a single incompressible Navier-Stokes (N$\mathrm{S}$ ) equation with effective properties depending upon the densities of the constituent gases (and particles if appropriate). The incompressible stress tensor is written (Landau and Lifshitz, 1987),

$\nabla \cdot \overline{\bar{\tau}}^{f}=-\nabla p^{\mathrm{f}}+\mu \nabla^{2} \mathbf{v}^{\mathrm{f}}$

where $p$ is the mechanical pressure and $\mu$ is the dynamic viscosity. We are not aware of compressibility effects considered in STRS modelling studies.

In the dilute fluidised regime, particles can often be assumed perfectly entrained in the flow for very small Stokes numbers $(<<1)$, simplifying the analysis by removing the need to track particle velocities or their statistical distribution independently. Relevant STRS studies using this approach include (Haussener et al., 2009; Martinek et al., 2012a; Martinek and Weimer, 2013a; Perkins and Weimer, 2007; Saade et al., 2012; Z'Graggen and Steinfeld, 2009). When the particles Stokes number is not so small to warrant the entrainment approximation, the interactions between the fluid and particle need to be resolved. In particle tracking methods, a finite representative number of particles are imbued with characteristics, including a drag coefficient, and are allowed to travel through the system and exchange mass, momentum, and energy with the surrounding flow. Abanades et al. demonstrated such an approach in (Abanades et al., 2007) and it was later emulated for a different geometry in (Muthusamy et al., 2014). Falling particle receivers fall into the category of dilute fluidised STRSs because it can be approximated that the particles do not directly interact with each other. However, gas entrainment is an important phenomenon in these systems as was accounted for in (Oles and Jackson, 2015) by using a semiphenomenological approach and more rigorously in (Chen et al., 2007) for non-reactive particles. The works discussed thus far consider flows with Reynolds numbers that are-or are assumed-low enough that laminar flow modelling is sufficient. To our knowledge, the paper by Groehn et al. (2016) represents the only STRS modelling study that considers a turbulent system; they utilise the $k-\omega$ turbulence model.
Dense fluidised systems introduce the very challenging task of resolving the particle-particle interactions of the multiphase fluid along with the fluid-particle interactions. The simplest route to model the momentum transfer in such systems is to sidestep a detailed, physics-based model and use empirical correlations such as those that are found in (Levenspiel, 1999) and (Kunii and Levenspiel, 1992). To our knowledge the only solar reactor modelling attempts in the literature that utilise this approach are found in studies of coal- or biomass-based STRSs. Momentum conservation in the dense fluidised systems studied in (Gordillo and Belghit, 2011a; Kenarsari and Zheng, 2014; Zedtwitz et al., 2007) were treated only implicitly by assuming plug flow and choosing a minimum fluidisation velocity calculated from an empirical correlation, and not at all in (von Zedtwitz and Steinfeld, 2005).

Outside of the solar-driven realm, more rigorous methodologies have been developed to handle the particle-particle and fluid-particle interactions with efforts that date back to the 1960s (Anderson and Jackson, 1967). A notable line of work stems from Gidaspow and co-workers (Ding and Gidaspow, 1990) where the kinetic theory of gasses was adapted to granular flows to statistically describe such systems resulting in effective fluid and solid phase hydrodynamic equations as in Eq. (6). Direct solution of the underlying kinetic equations is possible, but the discretisation of phase space results in many degrees of freedom per solution node resulting in a computationally expensive simulation. Closure relations are needed if the kinetic equations are reduced to hydrodynamic equations-like Eq. (6)-in terms of the macroscopic moments, such as the solid phase stress tensor, and often introduce a certain degree of empiricism. Detailed coverage of the body force terms and shear stresses appearing in Eq. (6) for the solids and gasses in dense fluidised systems are beyond the scope of this review as most do not appear explicitly in the STRS literature; a more complete description of the theory and associated expressions can be found in (Ding and Gidaspow, 1990; Gidaspow and Jiradilok, 2009). Their strategy provides a very promising route that appears in the STRS literature recently in the paper by Groehn et al. (2016). Their model of solid and fluid momentum transfer includes expressions for the solid phase stress tensor, as well as interphase momentum transfer by drag,

$\mathbf{f}_{\mathrm{v}}^{\xi}= \pm \beta\left(\mathbf{v}^{\mathrm{s}}-\mathbf{v}^{\mathrm{f}}\right)$.

Here $\beta$ is the coefficient for interphase force. The expressions are positive when appearing in the gas phase momentum equation and negative for the solid phase case. An expression for interphase momentum exchange because of mass exchange was also included. As an alternative approach, high performance computing now makes it possible to model these systems by simulating a tremendous number of individual particles; consult the review by Deen et al. (2007).

Momentum transfer modelling of fixed beds can be handled with some well-established methods from the more general field of flow through porous media. Homogenisation methods applied to the N-S equations can be shown to yield Darcy's law,

$-\nabla p^{\mathrm{f}}=\overline{\bar{K}}^{-1} \mu \mathbf{v}^{\mathrm{f}}$,

and the Dupuit-Forchheimer (D-F) extension,

$-\nabla p^{\mathrm{f}}=\overline{\bar{K}}^{-1} \mu \mathbf{v}^{\mathrm{f}}+F \rho^{\mathrm{f}}\left|\mathbf{v}^{\mathrm{f}}\right| \mathbf{v}^{\mathrm{f}}$,

a correction necessary when the Reynolds number is greater than unity (Suter et al., 2014). Here $\overline{\bar{K}}$ is the permeability tensor of the porous material and $F$ is the D-F coefficient. These expressions can replace Eq. (6) when describing momentum transfer in stationary porous structures. Both have appeared extensively in the STRS modelling literature either directly or semi-empirically and lead to the introduction of constants-namely the permeability and D- 
F coefficient-which must be determined experimentally, computationally (see Section 3), or from empirical models. An excellent discussion of Darcy's law, corrective terms, and determination of the permeability can be found in the monograph by Kaviany (1991). Momentum transfer can be neglected altogether when diffusion is the dominant mass transfer mechanism as found in the studies of porous calcium oxide/carbonate particles for carbon capture (Ebner and Lipiński, 2011, 2012). These studies were refined by including the relationship between pressure and velocity in Darcy's law which allowed the velocity field to be eliminated altogether and replaced by pressure in (Yue and Lipiński, 2015a,b,c). The approach was adopted from a study of reacting porous ceria in (Keene et al., 2013, 2014). Ströhle et al. used Ergun's equation-a form of Darcy's law with the Forchheimer correction-for the pressure drop through a packed bed of spheres (Ströhle et al., 2014).

A semi-heuristic approach of introducing inertial loss terms to the N-S equations stems from the work of Vafai and Tien (1981). Researchers have widely adopted this approach to model STRSs with porous active materials by assuming a viscous stress and local pressure gradient akin to the incompressible Navier-Stokes equations,

$\nabla \cdot \overline{\bar{\tau}}^{\mathrm{f}}=-\nabla p^{\mathrm{f}}+\mu^{\prime} \nabla^{2} \mathbf{v}^{\mathrm{f}}$.

Here $\mu^{\prime}$ is an effective viscosity appearing in a term known as the Brinkman viscous term (Whitaker, 1999; Kaviany,1991). Further, a Darcy loss term,

$\mathbf{f}_{\mathrm{D}}^{\mathrm{f}}=\overline{\bar{K}}^{-1} \mu \mathbf{v}^{\mathrm{f}}$,

as seen in (Martinek et al., 2014), or both Darcy and D-F loss terms,

$\mathbf{f}_{\mathrm{DF}}^{\mathrm{f}}=\overline{\bar{K}}^{-1} \mu \mathbf{v}^{\mathrm{f}}+F \rho^{\mathrm{f}}\left|\mathbf{v}^{\mathrm{f}}\right| \mathbf{v}^{\mathrm{f}}$,

have been added in Eq. (6) to account for momentum losses in the porous material as seen in (Bader et al., 2015; Bala Chandran et al., 2015a; Bala Chandran et al., 2015b; Lu et al., 2016; Villafán-Vidales et al., 2011; Wang et al., 2014a,b). The use of the Darcy term in Eq. (6) has been subject to debate (Whitaker, 1999; Kaviany, 1991). The inclusion of the advective term on the left-hand side of Eq. (6) may also have limited value when considering flow through pouous materials (Kaviany, 1991).

\subsection{Energy transfer}

The equation enforcing conservation of energy within STRSs accounts for the dominant energy transfer mechanisms within the reactor-conduction, convection, radiation, and enthalpy of reaction:

$\frac{\partial}{\partial t}\left(\sum_{j} \varepsilon^{\xi} \rho^{\xi} w_{j}^{\xi} h_{j}^{\xi}\right)+\nabla \cdot\left(\varepsilon^{\xi} \rho^{\xi} \mathbf{v}^{\xi} \sum_{j} w_{j}^{\xi} h_{j}^{\xi}\right)=\sum_{\mathrm{k}}\left(\dot{q}_{\mathrm{k}}^{\xi}-\dot{W}_{\mathrm{k}}^{\xi}\right)$.

We have chosen to write the energy equation in terms of specific enthalpy $h$. While many authors chose to use temperature as their dependent variable in the energy equation, we find this convention convenient since the enthalpy of reaction becomes naturally included in the energy conservation equation when reactions are present. The power per volume delivered to the control volume by heat and mass transfer and by (non-flow) work are given by $\dot{q}$ and $\dot{W}$, respectively. The work term is neglected in all studies surveyed here. Note that the reaction enthalpy term that may appear explicitly in some works, e.g. (Lipiński and Steinfeld, 2004; Lipiński et al., 2005, 2006), is implicitly contained in the first term on the left-hand side since

$\frac{\partial}{\partial t}\left(\sum_{j} \varepsilon^{\xi} \rho^{\xi} w_{j}^{\xi} h_{j}^{\xi}\right)=\sum_{j} \frac{\partial\left(\varepsilon^{\xi} \rho^{\xi} w_{j}^{\xi}\right)}{\partial t} h_{j}^{\xi}+\left(\varepsilon^{\xi} \rho^{\xi} w_{j}^{\xi}\right) \frac{\partial h_{j}^{\xi}}{\partial t}$.
The first term on the right-hand side represents the enthalpy change in a control volume due to the addition of the chemical species $j$ with an enthalpy $h$, as described by the species conservation equation (1); following substitution the reaction rates will directly appear. The second term represents the change in enthalpy of species $j$ in the control volume from thermal and flow effects.

Studies where the mass content of the particles or porous material are relatively larger, particularly in dense fluidised and stationary type STRSs, can necessitate the consideration of a local thermal non-equilibrium between phases where the gas and solid are assigned different temperatures at the same location in space after homogenisation. Thus, one energy conservation equation (15) is solved for each phase. The use of local thermal non-equilibrium (LTNE) appears widely in the literature when using homogenisation (Gordillo and Belghit, 2011a, 2011b; Groehn et al., 2016; Kenarsari and Zheng, 2014; Villafán-Vidales et al., 2011; Wang et al., 2014a; Wang et al., 2014b; Zedtwitz et al., 2007; Zedtwitz and Steinfeld, 2005) or when the phases are resolved individually (Abanades et al., 2007; Oles and Jackson, 2015), though there are examples of high solid fraction studies in fixed beds where the single temperature-or local thermal equilibrium (LTE)-assumption is made (Lapp et al., 2013; Lapp and Lipiński, 2014; Lu et al., 2016; Martinek et al., 2014). The approximation of LTE is valid when any local temperature differences between a fluid and a solid are much smaller than the temperature differences that appear in the whole system. More rigorous mathematical conditions in terms of length and time scales can be found in (Kaviany, 1991). Even at low densities of particles, a separate temperature for the solid phase has been used (Perkins and Weimer, 2007; Saade et al., 2012). Homogenised equations for high-temperature heat and mass transfer in a porous system of reducing and oxidising ceria were developed by Keene et al. (2013, 2014) assuming LTNE between the phases and found that the temperature difference between them was only as high as $2 \%$. Later studies that utilise this model assumed LTE (Bader et al., 2015; Bala Chandran et al., 2015a; Yue and Lipiński, 2015a,b,c). In another study, researchers allowed grains in a packed bed to have full temperature profiles by solving a spherically symmetric heat equation in representative sets of calcium oxide/hydroxide particles at a certain size and coupling the result to fluid-phase mass and energy balance equations (Ströhle et al., 2014). The study of a solar driven methane reforming reactor using a porous medium also assumed a LTNE condition between the fluid and solid phase but requires no mass transfer between the two since the process is based on catalysis and not redox cycling (Wang et al., 2014a,b). LTNE models require a volumetric heat transfer coefficient, $h_{\mathrm{sf}}$ (Nusselt number), defined by

$\dot{q}_{\mathrm{h}}^{\xi}= \pm h_{\mathrm{sf}} a\left(T^{\mathrm{s}}-T^{\mathrm{f}}\right)$.

Like the permeability and D-F coefficient, expressions for the volumetric heat transfer coefficient can be found from experiment, correlation, or direct computation on representative geometry as will be described in Section 3.1. Energy transfer in modelling studies of dense fluidised beds in the literature use coarse-grained, onedimensional LTNE models with correlations for the volumetric heat transfer coefficient (Gordillo and Belghit, 2011a; Kenarsari and Zheng, 2014; Zedtwitz et al., 2007; Zedtwitz and Steinfeld, 2005). Gordillo and Belghit (2011a) proposed a one-dimensional model that accounts for the existence of bubbles in the dense fluidised bed by essentially treating them as an independent phase by assigning them their own energy and mass balance equations.

The power per volume delivered to the control volume by thermal conduction is described by Fourier's law and is included in almost all modelling studies:

$\dot{q}_{\mathrm{d}}^{\xi}=\nabla \cdot\left(k^{\xi} \nabla T^{\xi}\right)$ 
The thermal conductivity is given by $k$ and the temperature $T$ must be determined from the local enthalpy of the phase. In dilute fluidised beds, conduction is generally considered in an effective gas phase and may be represented in both phases in the dense fluidised and stationary regimes.

Interphase enthalpy flux associated with mass transfer is described by the enthalpy associated with the mass flux in Eq. (3):

$\dot{q}_{s}^{\xi}= \pm \sum_{j} \dot{m}_{j}^{\mathrm{f}} a h_{j}^{\mathrm{f}}$.

Inclusion of enthalpy change due to mass diffusion for individual species has also been considered (Keene et al., 2013; Wang et al., 2014a; Yue and Lipiński, 2015a) as described by

$\dot{q}_{\mathrm{e}}^{\mathrm{f}}=\nabla \cdot\left(\sum_{j} h_{j}^{\mathrm{f}} D_{j} \nabla\left(\rho^{\mathrm{f}} w_{j}^{\mathrm{f}}\right)\right)$.

Some energy transfer mechanisms can be ignored or simplified by arguments based on dimensionless numbers. The work of Z'Graggen and Steinfeld $(2009,2008)$ reduce the complexity of their model-decoupling the momentum equation from the energy equation-by such considerations but were still able to obtain reasonably good agreement with experimental values for coke and water conversion and gas composition. In dilute fluidised systems, non-radiative energy transfer may be represented quite simply by a single energy equation when the particles are small and dilute enough to take on the local temperature of the surrounding fluid. This assumption allows a single-temperature heat equation to be solved with effective properties and a source term due to enthalpy of reaction as used in the works of Haussener et al. (2009) and Melchior et al. (2008, 2009).

Nonlinearity appears in several terms of the energy equation. Enthalpy, the fundamental quantity appearing in the energy equation, can be strongly dependent upon temperature though often assumed directly proportional to temperature with a constant specific heat despite the very large temperature ranges often encountered in STRSs. Studies such as (Keene et al., 2013; Lipiński and Steinfeld, 2004; Yue and Lipiński, 2015a,b,c) deal with the nonlinear temperature dependence of enthalpy by including the temperature dependence implicitly which allows for a natural inclusion of the enthalpy of formation when solving for the energy of individual gas and solid components. The use of a temperature dependent specific heat times a temperature in place of an enthalpy was used in (Gordillo and Belghit, 2011a; Lapp and Lipiński, 2014; Wang et al., 2014b) among others. Enthalpy of formation may also appear as a source term in the energy balance equation when considering a single-phase equation only. Enthalpy of reaction can be available experimentally or estimated by thermodynamic database software as demonstrated in (Villafán-Vidales et al., 2011). The temperature dependence of reaction rates is generally handled by assuming an Arrhenius-type law (see Section 3.2): (Ebner and Lipiński, 2012, 2011; Haussener et al., 2009; Lipiński and Steinfeld, 2004; Müller et al., 2008; Oles and Jackson, 2015; Schunk et al., 2009b; 2009a; Villafán-Vidales et al., 2015; Yue and Lipiński, 2015a,b,c; Zedtwitz et al., 2007; Zedtwitz and Steinfeld, 2005). Fluid density, specific heat and thermal conductivity can all also be strong functions of temperature, particularly for gasses; inclusion of these effects can be found, for example, in (Kenarsari and Zheng, 2014; Lu et al., 2016; Müller et al., 2008; Wang et al., 2014b).

The term arising in the energy equation due to local absorption of radiative power is given by the divergence of the radiative flux,

$\dot{q}_{\mathrm{r}}^{\xi}=\nabla \cdot q_{\mathrm{r}}$.

The inclusion of a strong radiation component in the energy conservation equation is an important aspect of the modelling strategy and warrants a stand-alone discussion as follows next.

\subsection{Radiative energy transfer}

Researchers estimate that the heat transfer in fluidised bed reactors operating above a temperature of $1100-1300 \mathrm{~K}$ is likely dominated by radiation (Yang et al., 2004). Radiation can be highly directional, intense, and directly irradiating the active material. It is the driving force of the heat transfer in the system which in turn drives the chemistry; understanding its influence on reactor design is critical. Modelling efforts have ranged from simple StephanBoltzmann law boundary conditions to the energy equation ( $\mathrm{Lu}$ et al., 2016) or a simplified volumetric treatment based on this law (Kenarsari and Zheng, 2014; Saade et al., 2012) to fully three-dimensional, spectrally resolved studies of participating media with gas radiation effects (Zedtwitz et al., 2007).

Active materials, regardless of the reactor regime, are generally modelled as a radiatively participating medium using the radiative transfer equation (RTE),

$\frac{1}{c} \frac{\partial I}{\partial t}+\widehat{s} \cdot \nabla I=-\left(\sigma_{\mathrm{s}}+\kappa\right) I+\kappa I_{\mathrm{b}}+\frac{\sigma_{\mathrm{s}}}{4 \pi} \int_{4 \pi} \Phi I^{\prime} d \Omega^{\prime}$,

where $I=I(\boldsymbol{x}, \hat{s}, \lambda, t)$ is the spectral specific intensity defined in terms of propagation direction $\hat{s}$ and wavelength $\lambda$ in addition to space and time. The $\mathrm{b}$ subscript denotes blackbody radiation, a known function of local temperature and wavelength. The quantities $\sigma_{\mathrm{s}}$ and $\kappa$ are the linear scattering and absorption coefficients which, in general, depend upon wavelength. The scattering phase function is given by $\Phi$. The solid angle $\Omega$ is defined by a twodimensional angle on the surface of a sphere and an integral over this quantity represents an integration of all propagation directions. The transient term is generally not considered since it varies on time scales that are very small compared to the timescales of other processes such as chemical reactions. There are standard, complete and accessible texts on the topic of thermal radiation in participating media, e.g. (Modest, 2013). From a solution to an RTE one can compute the local radiative source appearing in the energy equation, by projecting the amount of energy propagating in each direction and wavelength onto each direction of a coordinate system:

$\dot{q}_{\mathrm{r}}^{\xi}=\nabla \cdot \iint I \hat{s} \mathrm{~d} \Omega \mathrm{d} \lambda$.

If the radiative transfer equation (RTE) is assumed valid, as is done in all the studies discussed here, two new computational challenges are added to the ordinary space and time discretisation: accounting for the directional and spectral nature of thermal radiation. Numerous methodologies exist to discretise the angular component of the radiative transfer equation, and-more than the choice between the finite element and finite volume methods to discretise space-can lead to tremendously different predictions. The widely-used methods that will solve the RTE exactly in the limit of infinite angular resolution, for a certain wavelength, include the Monte Carlo method (MC), the discrete ordinate method (DO), the finite volume method (FV), and the zonal method. The MC method is based on stochastic ray tracing. It is perhaps the most popular method in the STRS modelling literature, likely due to the simplicity to program, scale, and include complicated spectral and directional properties. Studies employing the MC method include (Ebner and Lipiński, 2011; Jäger et al., 2009; Lapp et al., 2013; Lipiński and Steinfeld, 2005; Lipiński et al., 2006; Martinek and Weimer, 2013a; Zedtwitz et al., 2007; Zedtwitz and Steinfeld, 2005; Z'Graggen and Steinfeld, 2009; 2008). The finite volume method has been analysed for its applicability in STRS simulation in (Martinek and Weimer, 2013b). It was found that a hybrid MC/FV approach, that took the accuracy of the MC method with the easy compatibility of the FV with CFD solvers, was an "optimal" approach. Further studies from the Colorado 
group have used this hybrid method (Groehn et al., 2016; Martinek et al., 2012a). The DO is a discretisation approach that relies on replacing the specific intensity, which is continuous in propagation direction, with a finite number of specific intensities evaluated at certain propagation directions (abscissa), thus forming a quadrature for properties calculated by integrals over direction-internal energy density, heat flux, etc. It has appeared in several studies, likely because of its availability in the popular simulation package from ANSYS (Abanades et al., 2007; Chen et al., 2007; Haussener et al., 2009). The zonal method-a method relying on finite volumes (zones) and the concept of exchange areas-is used in (Oles and Jackson, 2015; Perkins and Weimer, 2007).

The inclusion of spectral properties in the RTE solution is also the subject of numerous approaches. The MC method very naturally includes arbitrarily complicated spectral behaviour and many of the references using MC listed above include it. Less precise approximations such as the band approximation with two bands have appeared (Chen et al., 2007; Haussener et al., 2009) as well as studies that ignore spectral dependence entirely-the grey approximation (Abanades et al., 2007; Groehn et al., 2016; Wang et al., 2014a,b). The radiative properties of gases have dramatic spectral variation, particularly at the high temperatures achieved in STRSs and may lead to vastly different results (Modest, 2013). The gases present in solar thermochemical reactors are not strong scatterers but are strongly spectrally selective absorbers and emitters. The accuracy of radiation modelling in high temperature chemically reacting systems-especially with participating particles-is limited then by the accuracy of the radiative properties of the gaseous components. This is an issue that has been extensively studied in the combustion community; further discussion can be found in the review by Viskanta and Mengüç (1987). To our knowledge, very few examples of gas radiation effects have been considered in STRS modelling studies. One can be found in the work of von Zedtwitz et al. (2007).

High computational cost and complexity can be an issue in resolving the spectral and directional components of radiation. Such considerations have led to STRS-specific approximations such as the diffusion approximation of Dombrovsky et al. (2007). The Rosseland diffusion approximation (RD) is an approximate solution to the RTE in the optically thick limit that allows the definition of an effective thermal conductivity (with a cubic temperature dependence) to be defined and simply added in the thermal conduction term of the energy equation. This approximation has found wide use in the literature among studies in the dense fluidised (Gordillo and Belghit, 2011a), and stationary (Bader et al., 2015; Bala Chandran et al., 2015a; Dombrovsky et al., 2009; Ebner and Lipiński, 2012; 2011; Gordillo and Belghit, 2011b; Keene et al., 2013, 2014; Lapp et al., 2013; Lapp and Lipiński, 2014; Lipiński and Steinfeld, 2004; Martinek et al., 2014; Müller et al., 2008; Yue and Lipiński, 2015b, 2015a, 2015c) regimes. A thermal conductivity correlation to account for radiation in optically thick media that behaves much like the RD was used in (Ströhle et al., 2014). The $p_{1}$ approximation does not require significantly more computational expense-a Helmholz equation must be solved everywhere in space-but can handle media that are more optically thin than the RD (Modest, 2013). The $p_{1}$ approximation has been used to study several STRS designs based on porous materials (Bala Chandran et al., 2015b; Villafán-Vidales et al., 2011; Wang et al., 2014a,b).

In the dilute fluidised regime, particles are separated by lengths on average much larger than the particle sizes themselves. This regime is the classic area of study of thermal radiative transfer in a participating medium with multiple but independent scattering where the RTE is strictly valid. Particles are generally considered or approximated as spherical which allows for the use of an exact solution to the electrodynamic scattering problem for a sphere, the
Lorenz-Mie solution, to get the necessary RTE parameters. This approach is found widely in the literature for the dilute fluidised case (Haussener et al., 2009; Martinek et al., 2012a; Martinek and Weimer, 2013a; Perkins and Weimer, 2007; Z'Graggen and Steinfeld, 2009). Jäger et al. uses a slightly modified Lorenz-Mie prediction to better fit experimental results (Jäger et al., 2009). The use of Lorenz-Mie theory to approximate the scattering properties of a porous material has also appeared on a few occasions (Keene et al., 2013, 2014; Yue and Lipiński, 2015a, 2015b, 2015c). We will revisit this concept in Section 3.4. Highly dense active materials may not have a significant amount of radiation penetrating the bulk of the solid, allowing for a simple treatment of radiation that only accounts for absorption, reflection and emission from surfaces as found in (Piatkowski and Steinfeld, 2008; Schunk et al., 2009b; 2009a; Villafán-Vidales et al., 2015).

\subsection{Thermal stress}

Thermal stress calculations for the materials in STRSs appear to have received limited attention in the published literature. Some examples exist including a study on thermally induced stress in irradiated particles (Dombrovsky and Lipiński, 2007) and briefly in the design of a reactor based on alumina tubes containing porous ceria particles (Bader et al., 2015). However, the temperature range of operation can be very broad for STRSs so the potential for high thermal stress, potentially causing failure, is of concern.

\subsection{Example 1: Indirectly irradiated multi-tube solar fluidised-bed reactor for steam gasification of carbon}

Martinek et al. (2012a,b) developed and used a numerical 3-D steady-state model to analyse an indirectly irradiated, fluidisedbed solar reactor for the steam gasification of carbon. The reactor is shown schematically in Fig. 2. It consists of a cylindrical cavity receiver with a rectangular, lateral, windowed aperture. The cavity contains multiple fluidised-bed reaction tubes made from SiC or Inconel. The reactant flow, a two-phase mixture of steam in an argon carrier gas flow containing nanometre-sized acetylene black particles, is introduced to the reaction tubes from the top in an aerosol flow configuration. The cavity walls are reflective and actively cooled to room temperature.

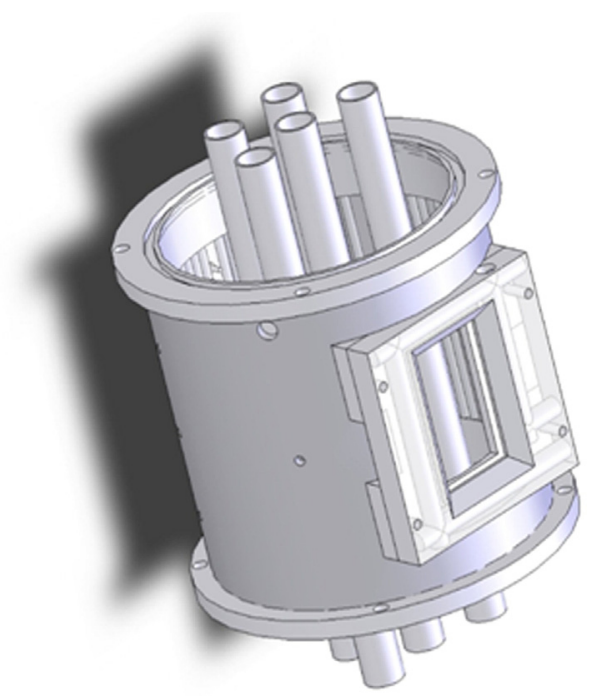

Fig. 2. Multi-tube solar fluidised-bed reactor. Reproduced with permission from (Martinek et al. 2012a). 
A hybrid MC/FV approach was used to model radiative heat transfer. The MC ray-tracing method was used to compute the heat flux on the tube and cavity surfaces inside the reactor due to solar radiation. In the MC solution, the spectral, directional reflectivity of the specular reactor inner surfaces was calculated from electromagnetic theory. The transfer of radiation originating from the hot inner and outer reaction tube surfaces was modelled by solving the radiative transfer equation with the FV method, using the same spatial mesh as for the solution of the mass, momentum, and energy conservation equations. In the FV model, the wavelength and directional dependence of the cavity surface reflectivity was neglected, while the window was modelled as grey with specular reflectivity calculated with Fresnel's equation. The particles were modelled as spherical and monodisperse with a diameter of $42 \mathrm{~nm}$. The absorption and scattering coefficients of the particle cloud were calculated via Lorenz-Mie theory and wavelengthaveraged with Planck's blackbody intensity distribution. Volumetric radiation absorption by the steam was included via a weighted sum of grey gases approach, while $\mathrm{CO}_{2}$ was assumed to be radiatively non-participating. The total volumetric absorption coefficient of the gas/particle suspension was obtained as the sum of those of the particles and the steam. The unpolished reaction tube surfaces were assumed to be opaque and diffuse-grey in both the MC and FV models.

The governing mass, species, momentum, and energy conservation equations were formulated based on a number of assumptions. Particles were assumed to be isothermal, based on the Biot number and characteristic heat transfer time estimations. Momentum and thermal Stokes numbers were estimated to be St,St $\mathrm{th}_{\mathrm{th}} \ll 1$. Hence differences in velocity and temperature between particles and fluid were considered negligible and only one mass, momentum, and energy conservation equation was solved for the mixture, using a volume-averaged mixture density and a mass-averaged mixture enthalpy. The fluid density was calculated with the ideal gas equation of state for the gas mixture. Both the forced convective flow inside the reaction tubes and the buoyancy-driven flow in the cavity were assumed to be laminar based on Re and Gr estimations. Viscous dissipation, kinetic energy, and diffusional energy transport were neglected in the energy equation. Separate species conservation equations were formulated for each gas species $(\mathrm{CO}$, $\mathrm{CO}_{2}, \mathrm{H}_{2}, \mathrm{H}_{2} \mathrm{O}$, and $\mathrm{Ar}$ ) and the particles. The particle species conservation equation considered the source term due to the gasification reaction, and transport via thermophoresis and Brownian motion. The effect of Brownian motion on particle transport was estimated to be minimal compared to convection, as $\mathrm{Sc}=\mu / \rho^{\mathrm{f}} D \gg 1$, but the term was retained for numerical stability.

In addition to the heterogeneous steam gasification reaction of carbon at the particle surface, the homogeneous water water-gas reaction was included, while the Boudouard reaction and hydrogasification were disregarded due to their slow reaction rates. The water-gas shift reaction was modelled as first-order in all gas components with an Arrhenius-type rate constant. The steam gasification reaction was modelled with a Langmuir-Hinshelwood kinetic expression with neglected inhibition by hydrogen.

Solutions for the system of coupled governing differential equations were computed simultaneously using the CFD software ANSYS FLUENT 6.3.26. Mesh parameters of $\sim 475,000$ spatial and $7 \times 7$ angular elements were determined with a mesh convergence study. The numerical model was validated via comparison of numerically predicted and experimentally measured cavity and tube wall temperatures and carbon conversion.

Besides the dependent variables of the governing equations (pressure, density, temperature, velocity field, radiative intensity distribution, species concentration), the model allows for the prediction of several additional quantities of interest, including the solar power input to each reaction tube, the reaction conversion, the reactor's overall absorption and solar-to-chemical energy conversion efficiencies, and the magnitudes of heat losses via different mechanisms. Example results are shown in Figs. 3 and 4. Fig. 3a shows the predicted solar radiative heat flux over the circumference of each of the five absorber tubes at the horizontal centre plane of the reactor. Strong variations can be observed over the tube circumferences and among the tubes, leading to significant temperature variations (Fig. $3 \mathrm{~b}$ ) and resulting in thermomechanical stresses in the tubes. Fig. 4 gives insight to the distribution of temperature and species mass fractions inside the centre tube. The results reveal strong axial temperature variations along the tube (Fig. 4a). In the directly irradiated centre region of the tube, temperatures are sufficiently high for the gasification reaction to proceed, while in the cooler exit region (lower part of the tube) $\mathrm{CO}_{2}$ is produced as a result of the water-gas shift reaction which is favoured at lower temperatures (Fig. 4b). The numerical model also allows for the consideration of theoretical cases. For example, in Fig. 4a the dotted line shows the centreline temperature in the absence of chemical reactions, and the dashed line shows the centreline temperature in absence of volumetric radiation absorption inside the tube, illustrating the important role of volumetric radiation absorption for heat transfer between tube wall and reactive flow.

Comprehensive multi-scale, multi-physics numerical models, as the above example, can provide excellent insight into the physical processes occurring in an STRS and, as such, can be instrumental tools for the optimisation of STRSs, as is demonstrated for example in (Martinek and Weimer, 2013a).

\subsection{Example 2: Directly irradiated porous ceria redox system}

Ceria (cerium dioxide) has been identified as a candidate redox material to split $\mathrm{H}_{2} \mathrm{O}$ and $\mathrm{CO}_{2}$ in solar thermochemical fuel production cycles (Chueh and Haile, 2010). Ceria reduces nonstoichiometrically without phase change, which is beneficial in terms of material stability, and also remains solid throughout the two-step cycle, which simplifies the separation of the gaseous products from the redox intermediary material. Keene et al. $(2013,2014)$ developed a transient numerical heat and mass transfer model of a two-phase system consisting of a porous ceria matrix subject to an inert sweep gas flow and direct concentrated solar radiation, undergoing thermochemical reduction (release of oxygen). The porous ceria structure simultaneously serves as the volumetric radiation absorber, oxygen exchange material, and reaction site for the heterogeneous oxygen exchange reaction between solid and gas phase. A schematic of the model system and images of two exemplary porous morphologies are shown in Fig. 5.

The system is modelled as axisymmetric, homogeneous, isotropic, and dimensionally stable (no geometrical changes of the solid). Concentrated solar radiation is incident at a flux of $1 \mathrm{MW} \mathrm{m}^{-2}$ on the fluid inlet plane at $z=0$ (Fig. 5a). The gas is assumed to be radiatively non-participating. Momentum conservation is described by Darcy's law. Volume-averaged mass and energy conservation equations are formulated and solved under the assumption of LTNE. The equations account for heat transfer by thermal conduction in both phases, radiative heat transfer in the solid phase, mass and enthalpy transport in the fluid phase by advection, interphase mass and associated enthalpy transfer, mass diffusion in the fluid phase and associated enthalpy transfer, and interphase convective heat transfer. The ceria structure is assumed to be optically thick and the Rosseland diffusion approximation is used to account for radiative heat transfer. Expressions are derived for the interphase oxygen exchange rate and associated enthalpy flux, 


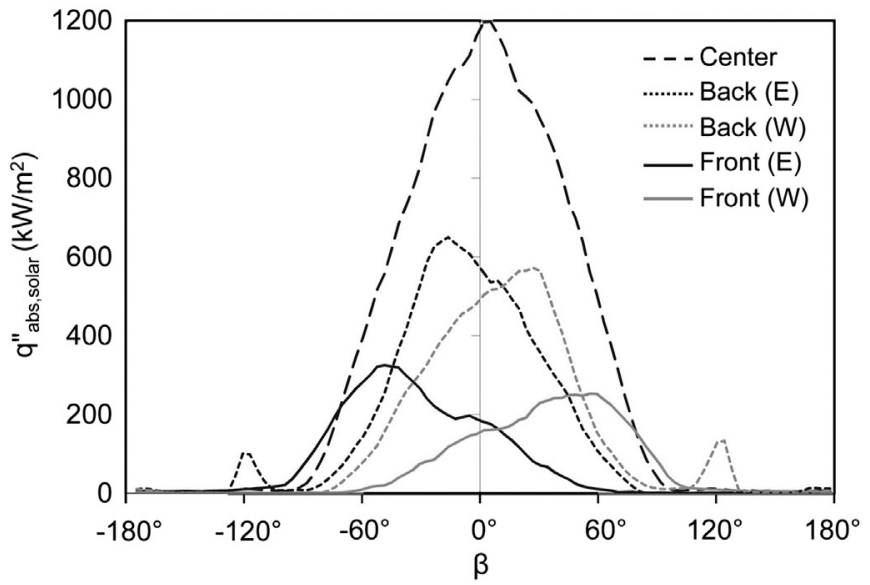

(a)

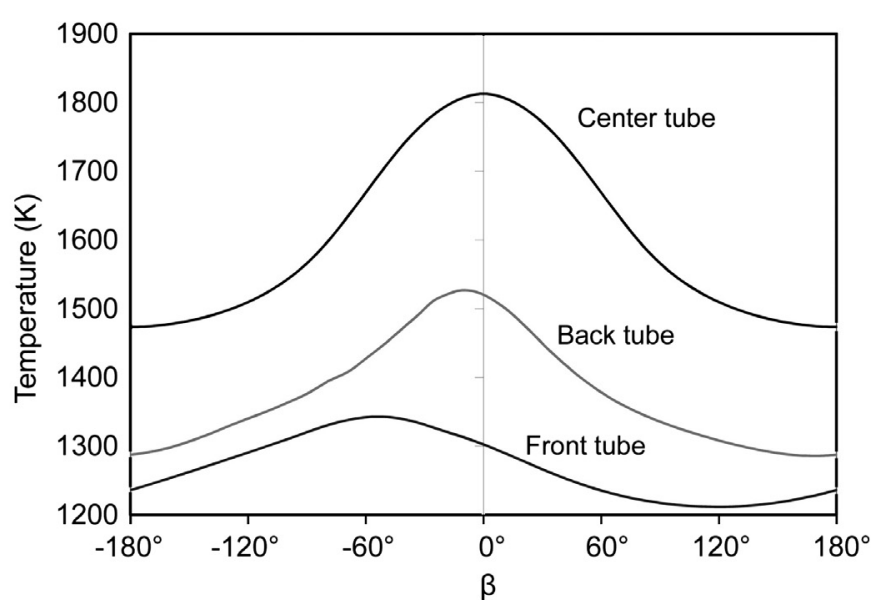

(b)

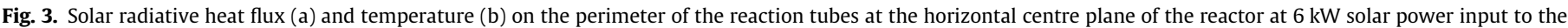
reactor. Reproduced with permission from (Martinek et al., 2012a).

(a)

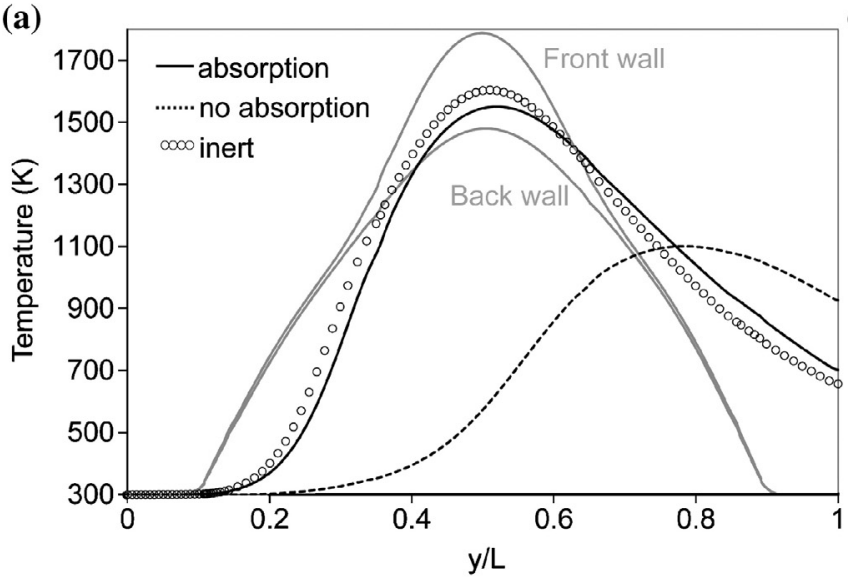

(b)

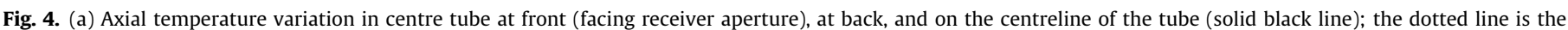

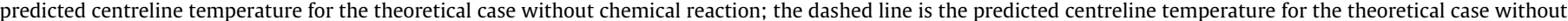
volumetric radiation absorption; (b) Mass fractions of $\mathrm{C}, \mathrm{CO}$, and $\mathrm{CO}_{2}$ in a vertical slice of the centre tube. Reproduced with permission from (Martinek et al., $2012 \mathrm{~b}$ ).

as functions of the solid temperature, gas-phase oxygen partial pressure, oxygen non-stoichiometry in the solid, and an unknown kinetic rate constant. The effective transport properties (permeability, interphase heat transfer coefficient, effective thermal conductivity) are obtained from models involving intrinsic transport properties (e.g. thermal conductivity, diffusion coefficient) and morphology-dependent parameters (e.g. porosity, specific surface area). The extinction coefficient is calculated from Lorenz-Mie theory in the geometric optics limit. The resulting set of governing differential equations is integrated in space with the finite volume method and in time with the implicit Euler method. Solutions are computed for a model domain of $10 \mathrm{~mm}$ diameter and 10 $\mathrm{mm}$ length on a structured cylindrical grid using 8000 elements, as determined in a grid refinement study.

Exemplary model results are shown in Fig. 6, for a fluid inlet mass flux of $0.3 \mathrm{~kg} \mathrm{~m}^{-2} \mathrm{~s}^{-1}$, fluid inlet temperature of $1000 \mathrm{~K}$, and a selected kinetic rate constant of $1 \mathrm{kmol} \mathrm{m}^{-2} \mathrm{~s}^{-1}$. Fig. 6a shows that the solid initially experiences a very large axial temperature gradient due to the high radiative heat input at $z=0$ and the high optical density of the solid, while heating of the downstream regions via thermal conduction, radiative heat exchange, and heat transfer via advection takes significantly longer. Comparison of Figs. $6 \mathrm{a}$ and $\mathrm{b}$ shows that the solid and gas temperatures closely match, except in a short inlet region, due to the high interphase convective heat transfer. Consequently, in future studies, the LTE assumption was made (Bader et al., 2015; Bala Chandran et al., 2015a). Fig. 6c shows that the evolution of the non-stoichiometry (i.e. the oxygen deficiency in the ceria lattice) is strongly nonuniform, as a result of the non-uniform axial temperature distribution and the build-up of oxygen in the gas flow, as shown in Fig. 6d. As the reaction nears completion (i.e. approaches the thermodynamic limit) near the inlet, the reaction rate slows down in this region and the location of the peak reaction rate travels downstream, as shown in Fig. 6e. In addition, the peak reaction rate decreases and the peak broadens as a result of the broadening axial temperature distribution (Fig. 6a).

These results illustrate the insights that numerical models can provide into the coupled heat and mass transport processes taking place in STRSs. The models developed by Keene et al. (2013) were subsequently used to analyse and optimise ceria-based porous 
(a)

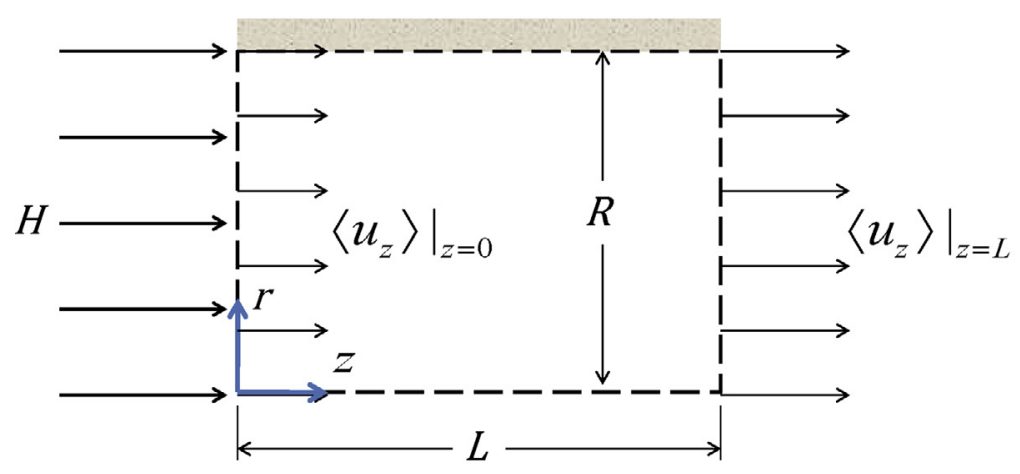

(b)
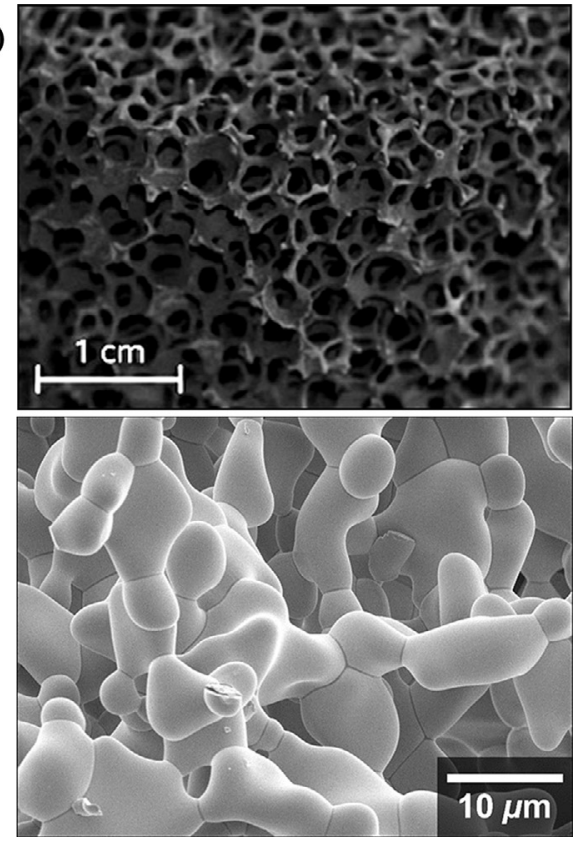

Fig. 5. (a) Model system. Reproduced with permission from (Keene et al., 2013). (b) Exemplary porous structures. Reproduced with permission from (Keene et al., 2014).

solid-gas STRSs at different scales. Keene et al. (2014) studied the effects of properties (i.e. porosity and Sauter mean diameter) on the rate of oxygen production and the solar-to-chemical energy conversion efficiency for a generic cylindrical volume. Other follow-up studies, conducted in ANSYS Fluent, predicted temperature, pressure, oxygen partial pressure and non-stoichiometry distributions in 3-dimensional model domains representing sections of actual solar prototype reactors (Bala Chandran et al., 2015a; Bader et al., 2015).

\section{Determination of properties}

STRSs have been proposed and designed to operate using many materials and configurations to achieve their chemical production goals. The thermophysical properties of the reacting solid material play a fundamental role in the design and operating conditions of a reactor. Some properties are simply unknown or difficult to measure; for example, the refractive index does not seem to be known as a function of reduction extent for non-stoichiometric redox materials such as ceria and doped ceria. In the following we highlight some of the efforts to quantify the transport, kinetic, and thermodynamic properties appearing in Section 2.

\subsection{Effective transport coefficients-computed tomography-based approaches}

The need for effective transport properties and closure relations has led to a line of study often carried out by the same research groups modelling the reactors themselves-parameter extraction by numerical solution on exact active-material-scale geometries. The use of computed tomography (CT) has become an important tool in these studies, allowing for the detailed geometry to be extracted from actual samples, as seen in Fig. 7. An overview of radiation in porous materials with morphology given by CT can be found in (Loretz et al., 2008). Detailed characterisations found in the literature include the determination of radiative properties of opaque reticulate porous structures (Petrasch et al., 2007) and semi-transparent packed beds (Haussener et al., 2010a) as well as effective thermal conductivity (Petrasch et al., 2008b), Darcy and D-F coefficients (Akolkar and Petrasch, 2012), and volumetric heat transfer coefficients (Petrasch et al., 2008a) for reticulate porous foams. These characterisations have been extended to porous materials with changing structure as a result of chemical reactions taking place (Haussener et al., 2010b; 2012), porous media with structural anisotropy (Haussener et al. 2012; Haussener and Steinfeld 2012; Suter and Haussener, 2013), and porous structures with dual-scale porosity (Ackermann et al., 2014b, 2017).

An accurate determination of the transport characteristics in random porous structures requires choosing a (set of) representative elementary volumes (REVs) for the calculations. REVs are the smallest sub-volumes of the sample that can be considered as continuum (Bear, 1988), and they represent a subset of the porous sample with, on average, the same structural characteristics and heterogeneities as the full sample. REVs can be determined by calculating morphological and transport properties in sub-volumes of the sample with increasing size until the results converge to a nearly constant value. REVs are generally determined based on morphological characteristics, such as porosity (Petrasch et al. 2008a,b,c), or specific volume (Suter et al., 2014). They are typically described by cubical volumes with edge lengths somewhere between 5 and 10 times the characteristics structural dimension of the sample (for example nominal pore diameter, or mean particle diameter). However, the necessary REV size based on transport characteristics is usually larger than the REV size based on morphological characteristics. For example, the edge length of a cubical REV for reticulate porous ceramics was calculated to be 2.5 times the nominal pore diameter while it was almost 6 times the nominal pore diameter if calculated based on the conductivity (Haussener et al., 2010c) (Fig. 8). Generally, REVs are highly dependent on the morphology and heterogeneity of the sample and the fabrication approach, and as a result they need to be investigated in detail before an in-depth transport characterisation can be done. Practically, the REV required can be larger than the field of view of the tomography experiment, which, in turn, is limited by the required resolution. In such a case, a statistical approach needs to be followed; multiple computed tomography datasets of different regions of the physical sample need to be obtained and used to determine the transport property as a statistical average obtained for the various sub-REV samples. 


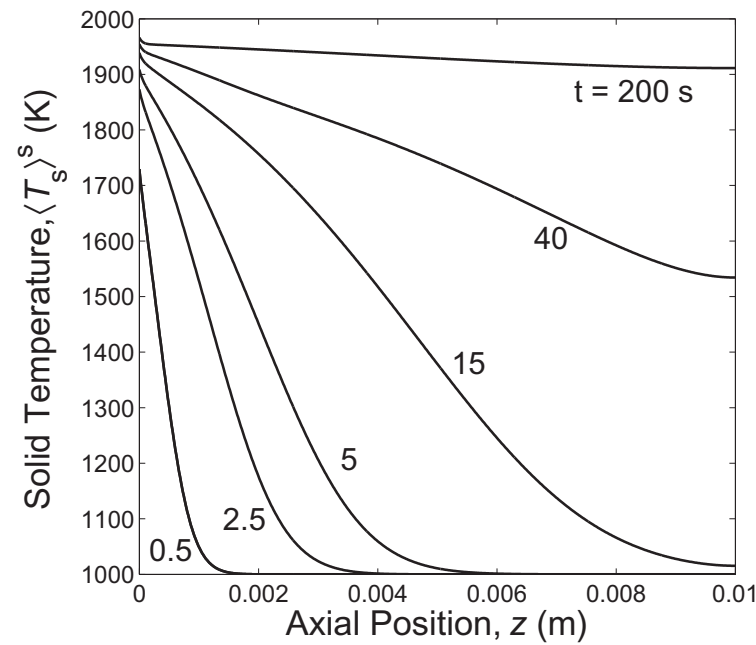

(a)

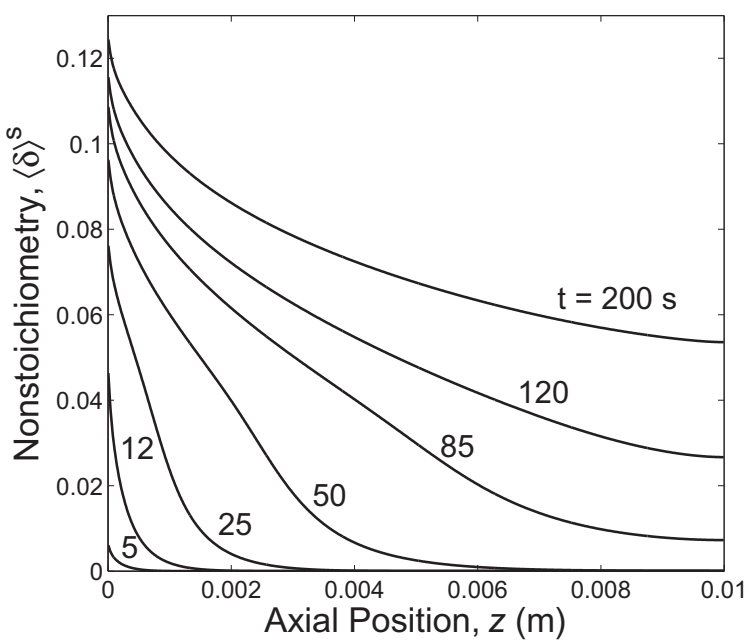

(c)

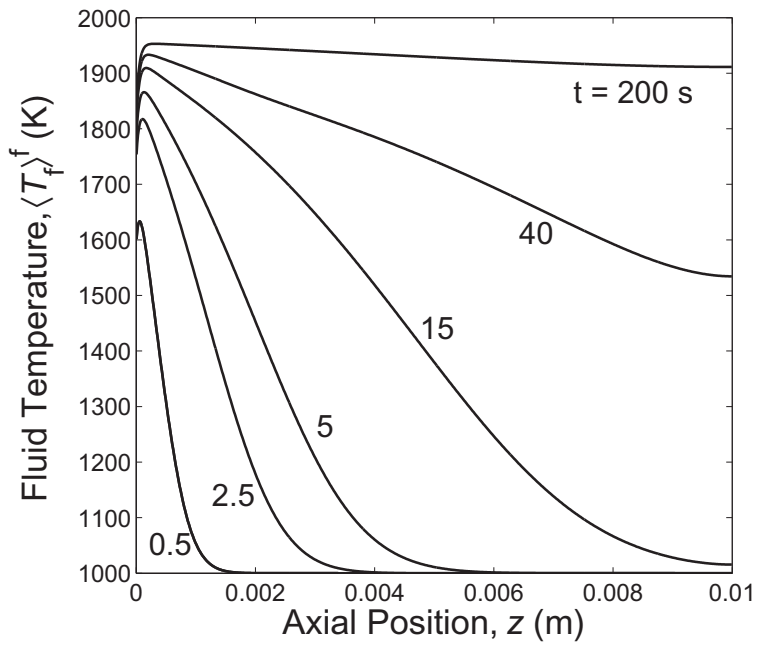

(b)

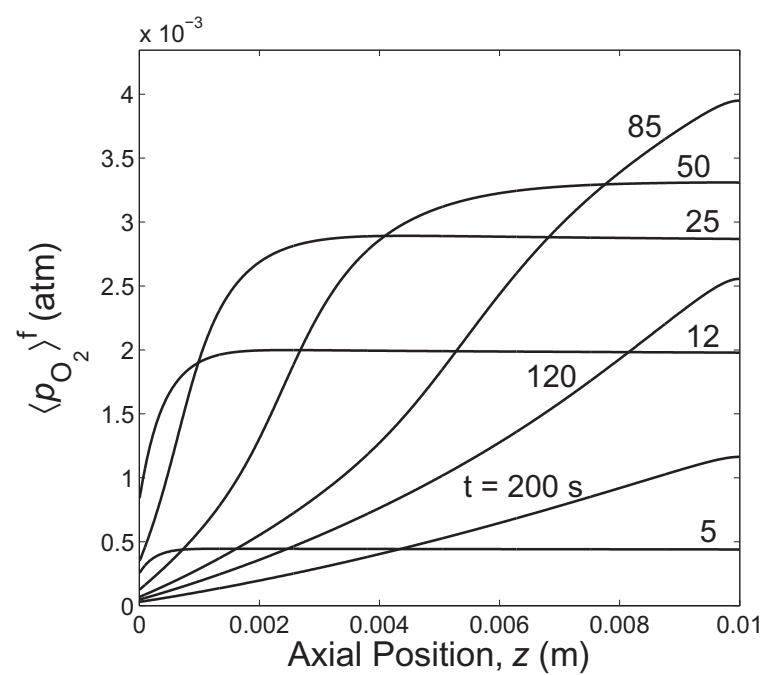

(d)

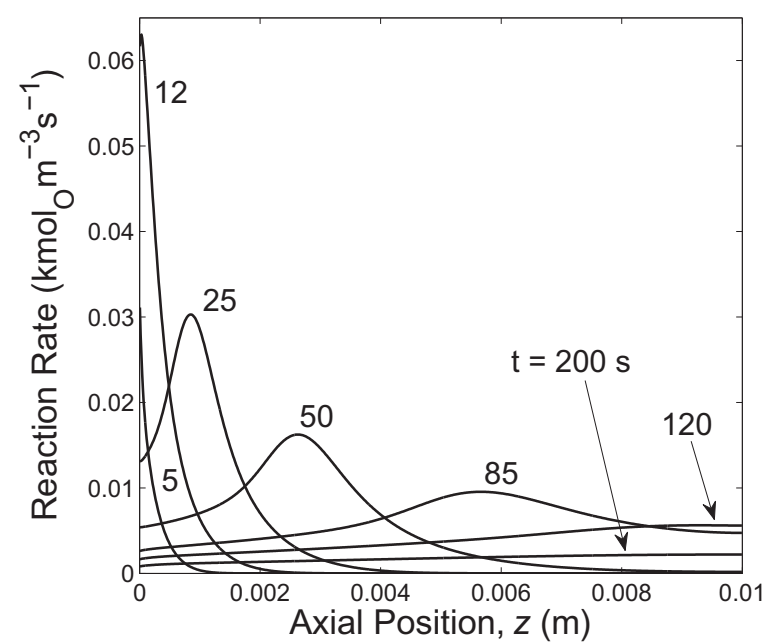

(e)

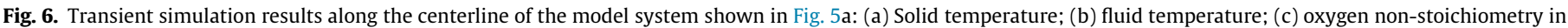
solid phase; (d) oxygen partial pressure in gas phase; (e) chemical reaction rate. Reproduced with permission from (Keene et al., 2013). 


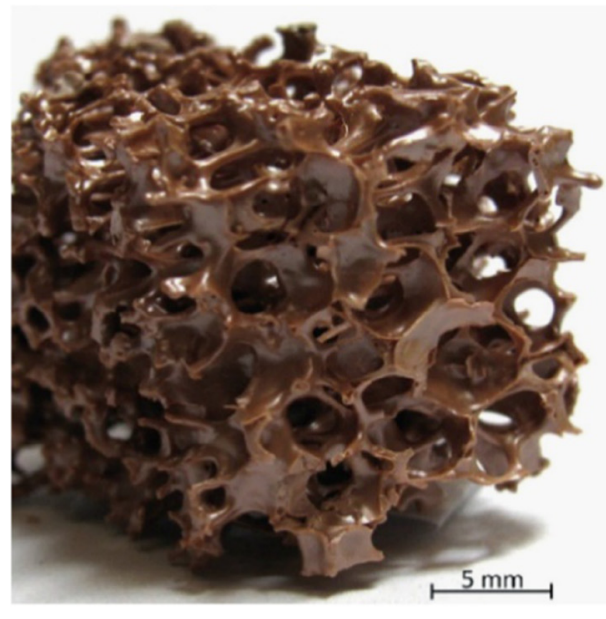

(a)

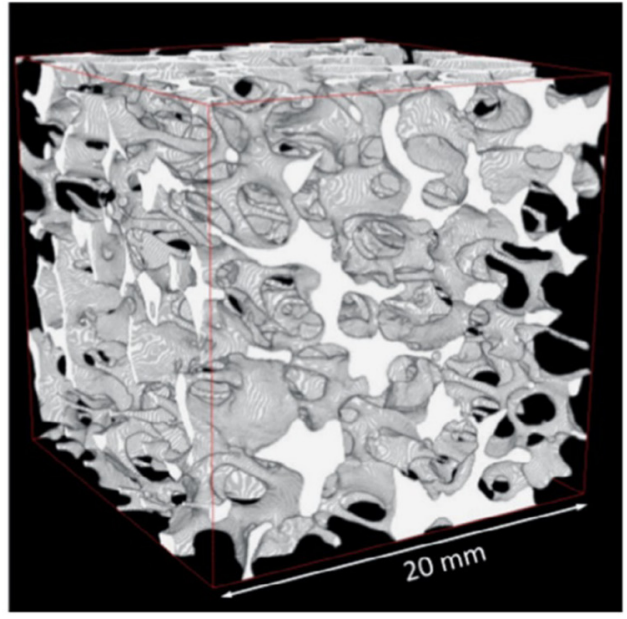

(b)

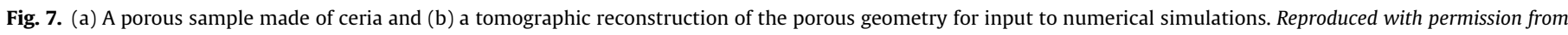
(Suter et al., 2014).

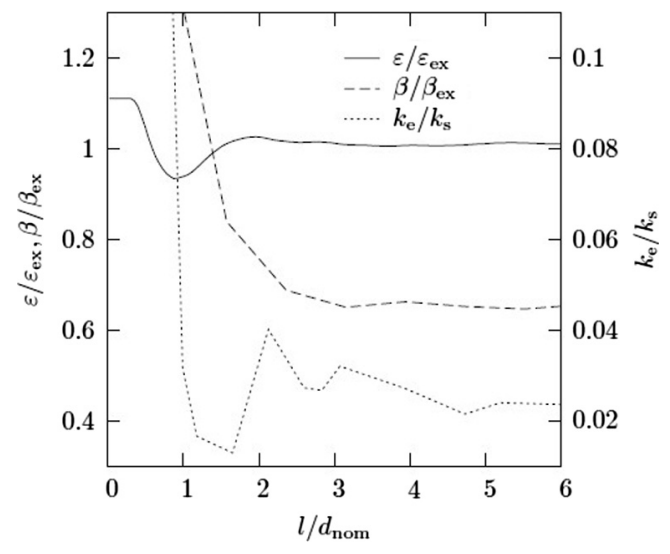

Fig. 8. Relative variation of calculated porosity and extinction coefficient (left $y$-axis) and effective thermal conductivity (right $y$-axis) as a function of the normalised edge length of the cubical calculation volume. With permission from (Haussener et al., 2010c).

Beyond characterising, authors have attempted to find optimised pore structures for STRS applications (Haussener et al. 2012; Akolkar and Petrasch, 2011, 2012; Suter et al., 2014; Suter and Haussener, 2013; Haussener and Steinfeld, 2012). The latest work in this line of research is a superset of previous works where the permeability, D-F coefficient, effective thermal conductivity, volumetric heat transfer coefficient, and effective extinction coefficient for porous ceria are found for reticulate porous ceria with changing porosity (Suter et al., 2014), and then applied in a simple 1D case to show the impact of morphology on the performance (Suter and Haussener, 2013).

Suter et al. (2014) investigated reticulate porous ceramic samples with porosities within a range of $0.45-0.85$, all for the same base morphology. The approach aimed at numerically recreating reticulate porous ceramic samples fabricated by the template method (Saggio-Woyansky et al., 1992) with an increasing number of slurry dipping steps, which resulted in samples with thicker and thicker struts and smaller and smaller porosities. This approach ensures that the potentially optimised morphology would also be fabricable. The tomography-based investigation showed that the sample's specific surface showed a maximum at an intermediate porosity, which was explained by the fact that the initially concave structures at high porosity, were slowly converted into convex structures at lower porosities. This trend for the specific surface area indicated that a foam structure of reacting material limited by surface area would require an intermediate porosity for best performance. All transport properties (permeability, D-F coefficient, volumetric heat transfer coefficient, conductivity, and extinction coefficient) monotonically increased or decreased with decreasing porosities. While this would generally result in a trivial structural optimisation for a physically decoupled process, it provides a rich optimisation problem with various local optima for the multi-physical process at hand. For example, a reduction in pressure drop would require highly porous structures, while an increase in radiation absorption would require a denser structure.

\subsection{Reaction kinetics}

In STRSs, the chemical reactions of interest typically occur at heterogenous solid-gas interfaces. These reactions include catalytic processing, gasification, pyrolysis, and oxidation/reduction (redox) driven multi-step thermochemical cycles. The metal oxide oxidation/reduction cycles are currently of significant interest in the solar thermochemical community, so this section will focus on those systems.

The kinetics of metal oxide redox pairs have been heavily explored as highlighted in Table 2. The studies on ferrite-based systems have shown that required reduction temperatures can be lowered by substituting metals such as manganese or nickel into ferrite based mixed metal oxides of the type $\mathrm{M}_{\mathrm{x}} \mathrm{Fe}_{3-\mathrm{x}} \mathrm{O}_{4}$ (Steinfeld, 2005). Co, Ni, Zn, Cu, and Mn substitutions into ferrite spinel structures have recently been used in successful hightemperature $\mathrm{H}_{2} \mathrm{O} / \mathrm{CO}_{2}$ splitting, suggesting that the $\mathrm{M}_{\mathrm{x}} \mathrm{Fe}_{3-\mathrm{x}} \mathrm{O}_{4}$ form of these mixed oxides is particularly active (Kodama et al., 2008; Gokon et al., 2011; Kodama et al., 2005; Rydén et al., 2011; Alvani et al., 2005; Tamaura et al., 1998; Hwang et al., 2004; Miller et al., 2008; Fresno et al., 2009; Fresno et al., 2010; Arifin et al., 2012; Gokon et al., 2008b; Agrafiotis et al., 2015; 2012; Goikoetxea et al., 2016; Lorentzou et al., 2014; Cha et al., 2007; Kodama et al., 2002). Other spinel structures are also of interest, such as the "hercynite cycle" (Muhich et al., 2013). The redox systems, including zinc oxide, ferrites, ceria, and other mixed metal oxide composite structures continue to receive much attention for their potential in solar thermochemical $\mathrm{CO}_{2}$-splitting and $\mathrm{H}_{2} \mathrm{O}$-splitting reactions (Agrafiotis et al., 2015; Furler et al., 2012; 
Table 2

Selected literature on kinetic studies of redox materials.

\begin{tabular}{ll}
\hline Reacting material & Kinetic study \\
\hline $\mathrm{Zn} / \mathrm{ZnO}$ & (Berman and Epstein, 2000; Möller and Palumbo, 2001; \\
& $\begin{array}{l}\text { Perkins et al., 2007; Schunk and Steinfeld, 2009; } \\
\text { Levêque and Abanades, 2014) }\end{array}$ \\
$\mathrm{SnO} / \mathrm{SnO}_{2}$ & (Chambon et al., 2009; Abanades, 2012) \\
$\mathrm{FeO} / \mathrm{Fe}_{3} \mathrm{O}_{4}$ & (Go et al., 2008; Loutzenhiser et al., 2009) \\
$\mathrm{MnO} / \mathrm{Mn}_{2} \mathrm{O}_{3}$ & (Francis et al., 2010; Botas et al., 2012) \\
$\mathrm{CoO} / \mathrm{Co}_{3} \mathrm{O}_{4}$ & (Neises et al., 2012; Karagiannakis et al., 2014) \\
$\mathrm{Mg} / \mathrm{MgO}_{\mathrm{Perovskites}}$ & (Gálvez et al., 2008) \\
$\mathrm{CeO}{ }_{2}$ & (McDaniel et al., 2014) \\
Doped and & (Stan et al., 2004) \\
undoped & (Kodama et al., 2008; Gokon et al., 2011; Kodama et al., \\
ferrites & 2005; Rydén et al., 2011; Alvani et al., 2005; Tamaura \\
& et al., 1998; Hwang et al., 2004; Miller et al., 2008; \\
& Fresno et al., 2009; Fresno et al., 2010; Arifin et al., \\
& 2012; Gokon et al., 2008b; Agrafiotis et al., 2015; \\
& Agrafiotis et al., 2012; Goikoetxea et al., 2016; \\
& Lorentzou et al., 2014; Cha et al., 2007; Kodama et al., \\
& 2002)
\end{tabular}

Gokon et al., 2008a; Han et al., 2007; Miller et al., 2008; Nakamura, 1977; Perkins and Weimer, 2004; Scheffe et al., 2010; 2013a; Stamatiou et al., 2010; Steinfeld et al., 1999). The metal oxide active materials in solar thermal water splitting operate via either a stoichiometric reduction pathway or via nonstoichiometric oxygen vacancy mechanisms (Muhich et al., 2016b). Many of the stoichiometric redox materials suffer from volatility issues (e.g. $\mathrm{ZnO}$ ) or other material handling issues such as the formation of unwanted intermediates and/or slag phases (e.g. $\mathrm{MFe}_{2} \mathrm{O}_{4}$ ) (Muhich et al., 2016b). The oxygen vacancy materials are generally more stable at high-temperature, but due to the nonstoichiometric nature of the reduction path, typically achieve smaller reduction extents which results in limited redox capacity and thus reduced fuel production (Muhich et al., 2016b).

The studies surrounding solid-state kinetics in STRSs generally describe solid-state chemical reaction rates using a form of the Arrhenius equation,

$\frac{\mathrm{d} \alpha}{\mathrm{d} t}=A e^{\left(\frac{-E_{\mathrm{a}}}{R T}\right)} f(\alpha)$,

written in terms of the conversion fraction $\alpha$ and the so-called kinetic triplet made up of a pre-exponential factor $A$, the activation energy $E_{\mathrm{a}}$, and the reaction model $f(\alpha)$ (Khawam and Flanagan, 2006). Here $T$ is the absolute temperature and $R$ is the gas constant. The conversion fraction is defined in terms of a normalised mass fraction,

$\alpha=\frac{m_{0}-m}{m_{0}-m_{\infty}}$

Here $m$ is mass and the subscripts 0 and $\infty$ denote the initial and final mass of the reacting material. The conversion fraction is the standard quantity used when studying reaction kinetics of a solid; it appears in terms of mass when using thermogravimetry but can also be written in terms of any measurement of chemical conversion extent such as gas phase product concentration measurements or X-ray diffraction crystal structure changes. The use of this experimental data directly in a continuum model as described in Section 2 requires some care since this is a bulk solid measurement that must be related to local gas/solid concentrations; see, for example (Barde et al., 2016).

The quantities $A$ and $E_{\mathrm{a}}$ are directly analogous to the preexponential factor and activation energy discussed in homogenous reaction kinetic studies. The reaction models $f(\alpha)$ are developed with mechanistic assumptions and are ideally based upon the physics of the reaction pathway in the heterogenous system, but they can also be empirically derived with little mechanistic meaning (Khawam and Flanagan, 2006). The physical structure of the active material at multiple length scales significantly affects diffusion and mass transport, heat transfer, and the mechanisms by which chemical reactions progress. Heat and mass transport limitations at both the solid-gas interface and within the solid material have important impacts on material performance, and should be considered when designing new materials and when modelling reacting systems (McDaniel, 2017; Miller et al., 2014b). Thus, an accurate determination of the reaction rate may rely upon a detailed understanding of the thermophysical processes described in Section 2.

The most commonly encountered solid-state reaction models are briefly summarised here: (i) nucleation and nuclei growth models describe processes such as crystallisation, decomposition, adsorption, and hydration that progress from nucleation sites such as imperfections, edges, and surfaces; (ii) geometrical contraction models describe reactions with rapid surface nucleation that are controlled by the progression of the reacting interface into the crystal structure; (iii) diffusion models describe systems that are limited by the rate at which reactants diffuse to the reaction site, such as gas molecules permeating into a crystal lattice; and (iv) order based models describe species-concentration-dependent reactions very similar to traditional chemical kinetic study in homogenous systems. The reactions that occur in the solid state can be a combination of several of the mechanisms discussed above. For example, in solar thermochemical water splitting using a cobalt ferrite-zirconia composite, Scheffe et al. (2013a) determined that both a first-order diffusion model and second-order reaction model are needed to adequately explain the reaction rate.

Extracting kinetic information from collected data in complex heterogenous solid-gas reactions must involve modelling the kinetic processes occurring in the solid state, but should also include treatment of $(i)$ the dispersion of gas phase species as they are evolved/consumed and as they flow downstream of a process, (ii) the time lag introduced using process equipment (e.g. valves, mass flow controllers, etc.), and (iii) the response/measurement effect of gas phase chemical analysis such as mass spectrometry (Muhich et al., 2015c; Scheffe et al., 2013a). In addition to the complexities of modelling the reacting system, there can be a large variation in the accuracy and agreement for empirically derived kinetic parameters from data using different extraction methodologies. Generally, the isoconversional methods developed by Vyazovkin can be used to avoid making unnecessary assumptions about reaction mechanisms and instead rely on minimising the error between experimental datasets and the modelled kinetics when estimating kinetic parameters (Vyazovkin and Wight, 1999; Vyazovkin, 1997; Vyazovkin and Lesnikovich, 1988).

\subsection{Material chemistry-ab initio methods}

$\mathrm{Ab}$ initio calculations using computational chemistry methods such as density functional theory (DFT) allow for theoretical determination of solid-state material properties such as crystal structure, lattice spacing, cation distributions, charge distribution on species in the lattice, and the energetics of specific states such as oxygen vacancies and transition states in reaction pathways (Botu et al., 2016; Balducci et al., 2003; Muhich et al., 2015a; Ganduglia-Pirovano et al., 2007; Deml et al., 2015; Michalsky et al., 2015a,b; Ezbiri et al., 2015; Dimitrakis et al., 2016; McDaniel, 2017). These calculations can provide great insight into mechanisms of the reaction pathway and the material properties that can limit or enhance active material performance. Recent works using DFT calculations to elucidate design principles for improved solar thermochemical cycle active materials have suggested that the thermodynamics of forming oxygen vacancies in a metal oxide lattice and the kinetics of conducting those vacancies 
to and from the surface are important in assessing material activity (Michalsky et al., 2015a,b; Ezbiri et al., 2015). Indeed, a study data mining first principles data from doped ceria studies identified surface oxygen vacancy formation energy as the primary descriptor that correlates with enhanced water splitting ability (Botu et al., 2016). Similar first principles O-vacancy and cation diffusion calculations have been carried out for ferrite based materials (Muhich et al., 2015b,a). Broadly, both computational and experimental results highlight the importance of oxygen vacancy diffusion in the bulk material (Miller et al., 2014b; Scheffe et al., 2013b; Ackermann et al., 2014b). More broad investigations into oxygen vacancies in metal oxides have also been completed (GandugliaPirovano et al., 2007; Deml et al., 2015).

First principles calculations to study material properties, as discussed above, can be used to tailor active materials in STRSs to maximise solar-to-chemical conversion efficiencies. Next generation metal oxides for solar thermochemical processing will need to have exceptional thermodynamic properties, appropriately fast reaction kinetics, and both mechanical and chemical stability. Paths to active material improvement include ( $i$ ) modification via substitution, (ii) hybridisation through support structures and the formation of solid solutions, and (iii) material structuring to finely tune properties such as mass transport (Miller et al., 2014a). Isovalent and aliovalent substitutions can be used to tailor bulk thermodynamic properties to promote higher redox capacity at less extreme conditions (McDaniel, 2017).

\subsection{Radiative properties-experimental and first principle studies}

In the dense fluidised and stationary regimes, the validity of using a RTE to govern thermal radiative transport is thrown into question since it has only been rigorously derived for discrete random media assuming the scatterers are far from each other (Mishchenko, 2010). Thus, the use of the radiative transport equation in porous media, may not be well-founded. However, while it is a dramatic geometrical approximation, it has been shown to agree well with experimental data when characterising porous ceria for STRS applications (Dombrovsky et al., 2012; Ganesan et al., 2013a). Simulations of effective radiative transfer (isolated from mass, momentum and other forms of energy transfer) motivated by STRS design have been carried out in conjunction with spectrophotometry set-ups to obtain effective radiative properties for packed beds and porous materials made of ceria (Dombrovsky et al., 2012; Ganesan et al., 2013a,b), zinc oxide (Coray et al., 2009; Schunk et al., 2009b), and a mixture of particles (Jäger et al., 2009).

Electrodynamic scattering calculations of individual particles allow for the determination of the scattering and absorption parameters needed for RTE-scale studies with dilute fluidised participating particulate media. Relevant computational approaches include the discrete dipole approximation (DDA), the finite element method (FEM), and the finite difference time domain method. Scattering from highly ordered ceria particles was considered in (Wheeler et al., 2014; Randrianalisoa and Lipiński, 2014) using FEM and DDA.

\section{Summary and outlook}

A large selection of the current literature using simulation techniques to understand the complex thermophysical phenomena occurring in STRSs has been surveyed. It is our hope that the inclusion of the precise mathematical expressions used to model STRSs at the continuum level to guide engineering design will be of archival value to the community trying to advance this technology to overcome the challenge laid out in Section 1: the use of transient, intense sunlight as a clean way to drive traditionally fossil-fuel- laden industries. Highlighted examples demonstrated the utilities of computational modelling of STRSs. Finally, an overview of property prediction for use in STRS models was given. In our review and discussion of numerical simulation of STRSs we have identified areas requiring further attention from researchers. We will conclude with a brief discussion of them.

STRS modelling is complicated, often involving large sets of coupled, non-linear partial differential equations and numerous physical constants. While ad hoc assumptions about material parameters and applicable models can be unavoidable because of a lack of experimental data or otherwise, we find that studies of the sensitivity of model results to such decisions-particularly when not comparing with experimental data-are essentially absent from the current literature. We believe such a practice should be more rigorously adopted in future studies.

A detailed understanding of the momentum and radiative transfer in the dense fluidised regime of reactor designs is no doubt challenging. However, the higher density of active material compared to dilute designs and the lower pressure drop of the sweep/reactive gas compared to fixed bed designs could make dense fluidised beds highly attractive for efficient STRS designs. Numerical studies resolving the detailed interactions within dense fluidised STRSs is a fruitful area of future research.

The inclusion of turbulence modelling in the STRS literature is very limited. The effect of turbulence on the mass, momentum, and heat transfer in STRSs could be dramatic by increasing solidgas heat transfer rates and more complete mixing of chemical species evolved from the reacting solid leading to more favourable partial pressure gradients near solid-gas surfaces. These effects could increase reaction rates.

The thermophysical properties of active materials may change dramatically throughout chemical changes and the high temperature and pressure changes that take place during STRS operation. Detailed knowledge of these properties is necessary for accurate reactor modelling but are often missing and/or approximated. Experimental determination of such properties, especially as new active materials are being identified, is important for accurate modelling of new STRS designs and therefore, the future development of STRSs in general.

A potential difficulty in the practical, large-scale realisation of STRSs is the highly transient nature of the solar input. Most studies assume some constant solar flux while the effect of, say, a passing cloud could be tremendously important for STRS operation. The effect of over- or under-irradiation of systems, particularly those with low thermal inertia such as dilute fluidised reactors, is an area that needs to be better understood.

The use of ab initio methods to understand the chemical properties of candidate materials is a new development that has enormous potential to identify materials for solar thermochemical processing that limits the need-or at least guides the directionfor trial and error material synthesis and characterisation. We think use of such methods will only grow.

\section{Acknowledgements}

Financial support from the Australian Renewable Energy Agency (Grant No. 2014/RND005) and the Australian Research Council (ARC Future Fellowship FT140101213 by W. Lipiński) is gratefully acknowledged.

\section{References}

Abanades, S., 2012. $\mathrm{CO}_{2}$ and $\mathrm{H}_{2} \mathrm{O}$ reduction by solar thermochemical looping using $\mathrm{SnO}_{2} / \mathrm{SnO}$ redox reactions: thermogravimetric analysis. Int. J. Hydrogen Energy 37, 8223-8231. http://dx.doi.org/10.1016/j.ijhydene.2012.02.158.

Abanades, S., Charvin, P., Flamant, G., 2007. Design and simulation of a solar chemical reactor for the thermal reduction of metal oxides: case study of zinc 
oxide dissociation. Chem. Eng. Sci. 62, 6323-6333. http://dx.doi.org/10.1016/j. ces.2007.07.042.

Ackermann, S., Scheffe, J.R., Steinfeld, A., 2014a. Diffusion of oxygen in ceria at elevated temperatures and its application to $\mathrm{H}_{2} \mathrm{O} / \mathrm{CO}_{2}$ splitting thermochemica redox cycles. J. Phys. Chem. C 118, 5216-5225. http://dx.doi.org/10.1021/ jp500755t.

Ackermann, S., Scheffe, J.R., Duss, J., Steinfeld, A., 2014b. Morphological characterization and effective thermal conductivity of dual-scale reticulated porous structures. Materials 7 (11), 7173-7195.

Ackermann, S., Takacs, M., Scheffe, J., Steinfeld, A., 2017. Reticulated porous ceria undergoing thermochemical reduction with high-flux irradiation. Int. J. Heat Mass Transf. 107, 439-449.

Agrafiotis, C., Roeb, M., Sattler, C., 2015. A review on solar thermal syngas production via redox pair-based water/carbon dioxide splitting thermochemical cycles. Renew. Sustain. Energy Rev. 42, 254-285.

Agrafiotis, C.C., Pagkoura, C., Zygogianni, A., Karagiannakis, G., Kostoglou, M., Konstandopoulos, A.G., 2012. Hydrogen production via solar-aided water splitting thermochemical cycles: combustion synthesis and preliminary evaluation of spinel redox-pair materials. Int. J. Hydrogen Energy 37, 89648980. http://dx.doi.org/10.1016/j.ijhydene.2012.02.196.

Akolkar, A., Petrasch, J., 2012. Tomography-based characterization and optimization of fluid flow through porous media. Transp. Porous Media 95, 535-550.

Akolkar, A., Petrasch, J., 2011. Tomography based pore-level optimization of radiative transfer in porous media. Int. J. Heat Mass Transf. 54, 4775-4783. http://dx.doi.org/10.1016/j.ijheatmasstransfer.2011.06.017.

Alonso, E., Romero, M., 2015. Review of experimental investigation on directly irradiated particles solar reactors. Renew. Sustain. Energy Rev. 41, 53-67. http://dx.doi.org/10.1016/j.rser.2014.08.027

Alvani, C., Ennas, G., La Barbera, A., Marongiu, G., Padella, F., Varsano, F., 2005. Synthesis and characterization of nanocrystalline $\mathrm{MnFe}_{2} \mathrm{O}_{4}$ : advances in thermochemical water splitting. Int. J. Hydrogen Energy 30, 1407-1411.

Anderson, T.B., Jackson, R., 1967. Fluid mechanical description of fluidized beds. Equations of motion. Ind. Eng. Chem. Fundam. 6 (4), 527-539.

Arifin, D., Aston, V.J., Liang, X., McDaniel, A.H., Weimer, A.W., 2012. CoFe ${ }_{2} \mathrm{O}_{4}$ on a porous $\mathrm{Al}_{2} \mathrm{O}_{3}$ nanostructure for solar thermochemical $\mathrm{CO}_{2}$ splitting. Energy Environ. Sci. 5, 9438-9443.

Bader, R., Bala Chandran, R., Venstrom, L.J., Sedler, S.J., Krenzke, P.T., De Smith, R.M., Banerjee, A., Chase, T.R., Davidson, J.H., Lipiński, W., 2015. Design of a solar reactor to split $\mathrm{CO}_{2}$ via isothermal redox cycling of ceria. J. Sol.Energy Eng. 137 031007.

Bader, R., Lipiński, W., 2016a. Solar thermal processing. In: Blanco, M., Ramirez, L.S. (Eds.), Advances in Concentrating Solar Thermal Research and Technology Woodhead Publishing (Elsevier), pp. 403-459.

Bader, R., Lipiński, W., 2016b. Solar thermochemical processes. In: Crawley, G.M. (Ed.), Solar Energy. World Scientific Publishing, New Jersey, pp. 345-394.

Bala Chandran, R., Bader, R., Lipiński, W., 2015a. Transient heat and mass transfer analysis in a porous ceria structure of a novel solar redox reactor. Int. J. Therm. Sci. 92, 138-149. http://dx.doi.org/10.1016/j.ijthermalsci.2015.01.016.

Bala Chandran, R., De Smith, R.M., Davidson, J.H., 2015b. Model of an integrated solar thermochemical reactor/reticulated ceramic foam heat exchanger for gasphase heat recovery. Int. J. Heat Mass Transf. 81, 404-414. http://dx.doi.org 10.1016/j.ijheatmasstransfer.2014.10.053.

Balducci, G., Islam, M.S., Kašpar, J., Fornasiero, P., Graziani, M., 2003. Reduction process in $\mathrm{CeO}_{2}-\mathrm{MO}$ and $\mathrm{CeO}_{2}-\mathrm{M}_{2} \mathrm{O}_{3}$ mixed oxides: a computer simulation study. Chem. Mater. 15, 3781-3785.

Bear, J., 1988. Dynamics in Fluids in Porous Media. Dover Publications Inc., New York.

Berman, A., Epstein, M., 2000. The kinetics of hydrogen production in the oxidation of liquid zinc with water vapor. Int. J. Hydrogen Energy 25, 957-967. http://dx. doi.org/10.1016/S0360-3199(00)00015-X.

Bohren, C.F., Huffman, D.R., 2004. Absorption and Scattering of Light by Small Particles. Wiley.

Barde, A.A., Klausner, J.F., Mei, R., 2016. Solid state reaction kinetics of iron oxide reduction using hydrogen as a reducing agent. Int. J. Hydrogen Energy 41 (24), 10103-10119.

Botas, J.A., Marugán, J., Molina, R., Herradón, C., 2012. Kinetic modelling of the first step of $\mathrm{Mn}_{2} \mathrm{O}_{3} \mathrm{MnO}$ thermochemical cycle for solar hydrogen production. Int. J. Hydrogen Energy 37, 18661-18671. http://dx.doi.org/10.1016/j.ijhydene. 2012.09.114.

Botu, V., Mhadeshwar, A., Suib, S., Ramprasad, R., 2016. Optimal dopant selection for water splitting with cerium oxides: mining and screening first principles data. In: Information Science for Materials Discovery and Design. Springer.

Cha, K.-S., Lee, D.-H., Jo, W.-J., Lee, Y.-S., Kim, Y.-H., 2007. Reaction characteristics of thermochemical methane reforming on ferrite-based metal oxide mediums Trans. Korean Hydrogen New Energy Soc. 18, 140-150.

Chambon, M., Abanades, S., Flamant, G., 2009. Kinetic investigation of hydrogen generation from hydrolysis of $\mathrm{SnO}$ and $\mathrm{Zn}$ solar nanopowders. Int. J. Hydrogen Energy 34, 5326-5336. http://dx.doi.org/10.1016/j.ijhydene.2009. 04.064

Chen, H., Chen, Y., Hsieh, H.-T., Siegel, N., 2007. Computational fluid dynamics modeling of gas-particle flow within a solid-particle solar receiver. J. Sol. Energy Eng. 129, 160-170.

Chueh, W.C., Haile, S.M., 2010. A thermochemical study of ceria: exploiting an old material for new modes of energy conversion and $\mathrm{CO}_{2}$ mitigation. Philos. Trans. Roy. Soc. A 368, 3269-3294.
Coray, P., Lipiński, W., Steinfeld, A., 2009. Experimental and numerical determination of thermal radiative properties of $\mathrm{ZnO}$ particulate media. J. Heat Transfer 132. http://dx.doi.org/10.1115/1.3194763. 012701-012701.

Deen, N., Annaland, M.V.S., der Hoef, M.V., Kuipers, J., 2007. Review of discrete particle modeling of fluidized beds. Chem. Eng. Sci. 62, 28-44. http://dx.doi.org/ 10.1016/j.ces.2006.08.014.

Deml, A.M., Holder, A.M., O’Hayre, R.P., Musgrave, C.B., Stevanovic, V., 2015. Intrinsic material properties dictating oxygen vacancy formation energetics in metal oxides. J. Phys. Chem. Lett. 6, 1948-1953.

Dimitrakis, D.A., Tsongidis, N.I., Konstandopoulos, A.G., 2016. Reduction enthalpy and charge distribution of substituted ferrites and doped ceria for thermochemical water and carbon dioxide splitting with DFT+U. Phys. Chem. Chem. Phys. 18, 23587-23595. http://dx.doi.org/10.1039/c6cp05073e.

Ding, J., Gidaspow, D., 1990. A bubbling fluidization model using kinetic theory of granular flow. AIChE J. 36, 523-538. http://dx.doi.org/10.1002/aic.690360404.

Dombrovsky, L., Lipiński, W., 2007. Transient temperature and thermal stress profiles in semi-transparent particles under high-flux irradiation. Int. J. Heat Mass Transf. 50, 2117-2123. http://dx.doi.org/10.1016/j. ijheatmasstransfer.2006.11.008.

Dombrovsky, L., Schunk, L., Lipiński, W., Steinfeld, A., 2009. An ablation model for the thermal decomposition of porous zinc oxide layer heated by concentrated solar radiation. Int. J. Heat Mass Transf. 52, 2444-2452. http://dx.doi.org/ 10.1016/j.ijheatmasstransfer.2008.12.025.

Dombrovsky, L.A., Ganesan, K., Lipiński, W., 2012. Combined two-flux approximation and Monte Carlo model for identification of radiative properties of highly scattering dispersed materials. Comput. Therm. Sci. 4 365-378. http://dx.doi.org/10.1615/ComputThermalScien. 2012005025.

Dombrovsky, L.A., Lipiński, W., Steinfeld, A., 2007. A diffusion-based approximate model for radiation heat transfer in a solar thermochemical reactor. J. Quant. Spectrosc. Radiat. Transfer 103, 601-610. http://dx.doi.org/10.1016/j. jqsit.2006.08.003.

Ebner, P.P., Lipiński, W., 2012. Heterogeneous thermochemical decomposition of a semi-transparent particle under high-flux irradiation-changing grain size versus shrinking core models. Num. Heat Transf., Part A: Appl. 62, 412-431. http://dx.doi.org/10.1080/10407782.2012.703466.

Ebner, P.P., Lipiński, W., 2011. Heterogeneous thermochemical decomposition of a semi-transparent particle under direct irradiation. Chem. Eng. Sci. 66, 26772689. http://dx.doi.org/10.1016/j.ces.2011.03.028.

Ezbiri, M., Allen, K.M., Gàlvez, M.E., Michalsky, R., Steinfeld, A., 2015. Design principles of perovskites for thermochemical oxygen separation. Chemsuschem 8, 1966-1971.

Floudas, C.A., Niziolek, A.M., Onel, O., Matthews, L.R., 2016. Multi-scale systems engineering for energy and the environment: Challenges and opportunities. AIChE J. 62, 602-623. http://dx.doi.org/10.1002/aic.15151.

Francis, T.M., Lichty, P.R., Weimer, A.W., 2010. Manganese oxide dissociation kinetics for the mn2o3 thermochemical water-splitting cycle. Part 1: experimental. Chem. Eng. Sci. 65, 3709-3717. http://dx.doi.org/10.1016/j. ces.2010.03.002

Fresno, F., Fernández-Saavedra, R., Gómez-Mancebo, M.B., Vidal, A., Sánchez, M., Rucandio, M.I., Quejido, A.J., Romero, M., 2009. Solar hydrogen production by two-step thermochemical cycles: evaluation of the activity of commercial ferrites. Int. J. Hydrogen Energy 34, 2918-2924.

Fresno, F., Yoshida, T., Gokon, N., Fernández-Saavedra, R., Kodama, T., 2010. Comparative study of the activity of nickel ferrites for solar hydrogen production by two-step thermochemical cycles. Int. J. Hydrogen Energy 35, 8503-8510.

Furler, P., Scheffe, J., Gorbar, M., Moes, L., Vogt, U., Steinfeld, A., 2012. Solar thermochemical $\mathrm{CO}_{2}$ splitting utilizing a reticulated porous ceria redox system. Energy Fuels 26, 7051-7059. http://dx.doi.org/10.1021/ef3013757.

Ganduglia-Pirovano, M.V., Hofmann, A., Sauer, J., 2007. Oxygen vacancies in transition metal and rare earth oxides: current state of understanding and remaining challenges. Surf. Sci. Rep. 62, 219-270.

Ganesan, K., Dombrovsky, L.A., Lipiński, W., 2013a. Visible and near-infrared optical properties of ceria ceramics. Infrared Phys. Technol. 57, 101-109. http://dx.doi. org/10.1016/j.infrared.2012.12.040.

Ganesan, K., Randrianalisoa, J., Lipiński, W., 2013b. Effect of morphology on spectral radiative properties of three-dimensionally ordered macroporous ceria packed bed. J. Heat Transfer 135. http://dx.doi.org/10.1115/1.4024942. 122701122701.

Gálvez, M.E., Frei, A., Albisetti, G., Lunardi, G., Steinfeld, A., 2008. Solar hydrogen production via a two-step thermochemical process based on $\mathrm{MgO} / \mathrm{Mg}$ redox reactions-thermodynamic and kinetic analyses. Int. J. Hydrogen Energy 33, 2880-2890. http://dx.doi.org/10.1016/j.ijhydene.2008.04.007.

Gidaspow, D., Jiradilok, V., 2009. Computational Techniques: The Multiphase CFD Approach to Fluidization and Green Energy Technologies. Nova.

Go, K.S., Son, S.R., Kim, S.D., 2008. Reaction kinetics of reduction and oxidation of metal oxides for hydrogen production. Int. J. Hydrogen Energy 33, 5986-5995. http://dx.doi.org/10.1016/j.ijhydene.2008.05.039.

Goikoetxea, N.B., Gómez-Mancebo, M.B., Fernández-Saavedra, R., García-Pérez, F. Jiménez, J.A., Rodríguez, J., Rucandio, I., Quejido, A.J., 2016. Study of the performance of $\mathrm{Co}$ and $\mathrm{Ni}$ ferrites after several cycles involved in water-splitting thermochemical cycles. Int. J. Hydrogen Energy 41, 16696-16704. http://dx.doi. org/10.1016/j.ijhydene.2016.07.085.

Gokon, N., Hasegawa, T., Takahashi, S., Kodama, T., 2008a. Thermochemical twostep water-splitting for hydrogen production using Fe-YSZ particles and a 
ceramic foam device. Energy 33, 1407-1416. http://dx.doi.org/10.1016/j. energy.2008.04.011.

Gokon, N., Mataga, T., Kondo, N., Kodama, T., 2011. Thermochemical two-step water splitting by internally circulating fluidized bed of $\mathrm{NiFe}_{2} \mathrm{O}_{4}$ particles: successive reaction of thermal-reduction and water-decomposition steps. Int. J. Hydrogen Energy 36, 4757-4767.

Gokon, N., Takahashi, S., Yamamoto, H., Kodama, T., 2008b. Thermochemical twostep water-splitting reactor with internally circulating fluidized bed for thermal reduction of ferrite particles. Int. J. Hydrogen Energy 33, 2189-2199.

Gordillo, E., Belghit, A., 2011a. A bubbling fluidized bed solar reactor model of biomass char high temperature steam-only gasification. Fuel Process. Technol. 92, 314-321. http://dx.doi.org/10.1016/j.fuproc.2010.09.021.

Gordillo, E., Belghit, A., 2011b. A downdraft high temperature steam-only solar gasifier of biomass char: a modelling study. Biomass Bioenerg. 35, 2034-2043. http://dx.doi.org/10.1016/j.biombioe.2011.01.051.

Groehn, A.J., Lewandowski, A., Yang, R., Weimer, A.W., 2016. Hybrid radiation modeling for multi-phase solar-thermal reactor systems operated at high-temperature. Sol. Energy 140, 130-140. http://dx.doi.org/10.1016/j.solener.2016.11.003.

Han, S.B., Kang, T.B., Joo, O.S., Jung, K.D., 2007. Water splitting for hydrogen production with ferrites. Sol. Energy 81, 623-628. http://dx.doi.org/10.1016/ j.solener.2006.08.012.

Haussener, S., Hirsch, D., Perkins, C., Weimer, A., Lewandowski, A., Steinfeld, A., 2009. Modeling of a multitube high-temperature solar thermochemical reactor for hydrogen production. J. Sol.Energy Eng. 131. http://dx.doi.org/10.1115/ 1.3097280. 024503-024503.

Haussener, S., Jerjen, I., Wyss, P., Steinfeld, A., 2012. Tomography-based determination of effective transport properties for reacting porous media. J. Heat Transfer 134. http://dx.doi.org/10.1115/1.4004842. 012601-012601.

Haussener, S., Steinfeld, A., 2012. Effective heat and mass transport properties of anisotropic porous ceria for solar thermochemical fuel generation. Materials 5 (1), 192-209.

Haussener, S., Lipiński, W., Petrasch, J., Wyss, P., Steinfeld, A., 2010a. Tomographic characterization of a semitransparent-particle packed bed and determination of its thermal radiative properties. J. Heat Transfer 131. http://dx.doi.org/10.1115/ 1.3109261. 072701-072701.

Haussener, S., Lipiński, W., Wyss, P., Steinfeld, A., 2010b. Tomography-based analysis of radiative transfer in reacting packed beds undergoing a solid-gas thermochemical transformation. J. Heat Transfer 132. http://dx.doi.org/ 10.1115/1.4000749. 061201-061201.

Haussener, S., Coray, P., Lipiński, W., Wyss, P., Steinfeld, A., 2010c. Tomographybased heat and mass transfer characterization of reticulate porous ceramics for high-temperature processing. J. Heat Transfer 132 (2), 023305. http://dx.doi. org $/ 10.1115 / 1.4000226$

Hinds, W.C., 2012. Aerosol Technology: Properties, Behavior, and Measurement of Airborne Particles. John Wiley \& Sons.

Hwang, G.-J., Park, C.-S., Lee, S.-H., Seo, I.-T., Kim, J.-W., 2004. Ni-ferrite-based thermochemical cycle for solar hydrogen production. J. Ind. Eng. Chem.-Seoul $10,889-893$.

Jakobsen, H.A., 2014. Chemical Reactor Modeling: Multiphase Reactive Flows. Second ed. Springer, New York.

Jäger, K., Lipiński, W., Katzgraber, H.G., Steinfeld, A., 2009. Determination of thermal radiative properties of packed-bed media containing a mixture of polydispersed particles. Int. J. Therm. Sci. 48, 1510-1516. http://dx.doi.org/10.1016/j. ijthermalsci.2008.12.006.

Karagiannakis, G., Pagkoura, C., Zygogianni, A., Lorentzou, S., Konstandopoulos, A.G., 2014. Monolithic ceramic redox materials for thermochemical heat storage applications in CSP plants. Energy Proc. 49, 820-829. http://dx.doi.org/10.1016/ j.egypro.2014.03.089.

Kaviany, M., 1991. Principles of Heat Transfer in Porous Media. Springer.

Keene, D.J., Davidson, J.H., Lipiński, W., 2013. A model of transient heat and mass transfer in a heterogeneous medium of ceria undergoing nonstoichiometric reduction. J. Heat Transfer 135. http://dx.doi.org/10.1115/1.4023494. 052701052701.

Keene, D.J., Lipiński, W., Davidson, J.H., 2014. The effects of morphology on the thermal reduction of nonstoichiometric ceria. Chem. Eng. Sci. 111, 231-243. http://dx.doi.org/10.1016/j.ces.2014.01.010.

Kenarsari, S.D., Zheng, Y., 2014. $\mathrm{CO}_{2}$ gasification of coal under concentrated thermal radiation: a numerical study. Fuel Process. Technol. 118, 218-227. http://dx.doi. org/10.1016/j.fuproc.2013.09.005.

Khawam, A., Flanagan, D.R., 2006. Solid-state kinetic models: basics and mathematical fundamentals. J. Phys. Chem. B 110, 17315-17328.

Kodama, T., Gokon, N., Yamamoto, R., 2008. Thermochemical two-step water splitting by $\mathrm{ZrO}_{2}$-supported $\mathrm{Ni}_{x} \mathrm{Fe}_{3-x} \mathrm{O}_{4}$ for solar hydrogen production. Sol. Energy 82, 73-79.

Kodama, T., Kondoh, Y., Yamamoto, R., Andou, H., Satou, N., 2005. Thermochemical hydrogen production by a redox system of $\mathrm{ZrO}_{2}$-supported $\mathrm{Co}$ (ii)-ferrite. Sol. Energy 78, 623-631.

Kodama, T., Shimizu, T., Satoh, T., Nakata, M., Shimizu, K.-I., 2002. Stepwise production of Co-rich syngas and hydrogen via solar methane reforming by using a Ni(ii)-ferrite redox system. Sol. Energy 73, 363-374.

Kunii, D., Levenspiel, O., 1992. Fluidization Engineering. Butterworth-Heinemann, Sydney.

Landau, L., Lifshitz, E., 1987. Fluid Mechanics. Pergamon, Sydney.

Lapp, J., Davidson, J.H., Lipiński, W., 2013. Heat transfer analysis of a solid-solid heat recuperation system for solar-driven nonstoichiometric redox cycles. J. Sol. Energy Eng. 135. http://dx.doi.org/10.1115/1.4023357. 031004-031004.
Lapp, J., Lipiński, W., 2014. Transient three-dimensional heat transfer model of a solar thermochemical reactor for $\mathrm{H}_{2} \mathrm{O}$ and $\mathrm{CO}_{2}$ splitting via nonstoichiometric ceria redox cycling. J. Sol.Energy Eng. 136. http://dx.doi.org/10.1115/1.4026465. 031006-031006.

Levenspiel, O., 1999. Chemical Reaction Engineering. Wiley.

Levêque, G., Abanades, S., 2014. Design and operation of a solar-driven thermogravimeter for high temperature kinetic analysis of solid-gas thermochemical reactions in controlled atmosphere. Sol. Energy 105, 225235. http://dx.doi.org/10.1016/j.solener.2014.03.022.

Lipiński, W., Steinfeld, A., 2005. Transient radiative heat transfer within a suspension of coal particles undergoing steam gasification. Heat Mass Transf. 41, 1021-1032. http://dx.doi.org/10.1007/s00231-005-0654-5.

Lipiński, W., Steinfeld, A., 2004. Heterogeneous thermochemical decomposition under direct irradiation. Int. J. Heat Mass Transf. 47, 1907-1916. http://dx.doi. org/10.1016/j.ijheatmasstransfer.2003.10.010.

Lipiński, W., Z'Graggen, A., Steinfeld, A., 2005. Transient radiation heat transfer within a nongray nonisothermal absorbing-emitting-scattering suspension of reacting particles undergoing shrinkage. Num. Heat Transf., Part B: Fund. 47, 443-457. http://dx.doi.org/10.1080/10407790590928955.

Lipiński, W., Davidson, J.H., Haussener, S., Klausner, J.F., Mehdizadeh, A.M., Petrasch, J., Steinfeld, A., Venstrom, L., 2013. Review of heat transfer research for solar thermochemical applications. J. Therm. Sci. Eng. Appl. 5. http://dx.doi.org/ $10.1115 / 1.4024088$

Lipiński, W., Keene, D., Haussener, S., Petrasch, J., 2010a. Continuum radiative heat transfer modeling in media consisting of optically distinct components in the limit of geometrical optics. J. Quant. Spectrosc. Radiat. Transfer 111, 2474-2480. http://dx.doi.org/10.1016/j.jqsrt.2010.06.022.

Lipiński, W., Petrasch, J., Haussener, S., 2010b. Application of the spatial averaging theorem to radiative heat transfer in two-phase media. J. Quant. Spectrosc Radiat. Transfer 111, 253-258. http://dx.doi.org/10.1016/j.jqsrt.2009.08.001.

Lipiński, W., Thommen, D., Steinfeld, A., 2006. Unsteady radiative heat transfer within a suspension of $\mathrm{ZnO}$ particles undergoing thermal dissociation. Chem. Eng. Sci. 61, 7029-7035. http://dx.doi.org/10.1016/j.ces.2006.07.037.

Lorentzou, S., Karagiannakis, G., Pagkoura, C., Zygogianni, A., Konstandopoulos, A. 2014. Thermochemical $\mathrm{Co}_{2}$ and $\mathrm{CO}_{2} / \mathrm{H}_{2}$ o splitting over $\mathrm{NiFe}_{2} \mathrm{O}_{4}$ for solar fuels synthesis. Energy Proc. 49, 1999-2008.

Loretz, M., Maire, E., Baillis, D., 2008. Analytical modelling of the radiative properties of metallic foams: contribution of X-ray tomography. Adv. Eng. Mater. 10, 352-360. http://dx.doi.org/10.1002/adem.200700334.

Loutzenhiser, P.G., Gálvez, M.E., Hischier, I., Stamatiou, A., Frei, A., Steinfeld, A., 2009. $\mathrm{CO}_{2}$ splitting via two-step solar thermochemical cycles with $\mathrm{Zn} / \mathrm{ZnO}$ and $\mathrm{FeO} / \mathrm{Fe}_{3} \mathrm{O}_{4}$ redox reactions II: kinetic analysis. Energy Fuels 23, 2832-2839. http://dx.doi.org/10.1021/ef801142b.

Lu, J., Chen, Y., Ding, J., Wang, W., 2016. High temperature energy storage performances of methane reforming with carbon dioxide in a tubular packed reactor. Appl. Energy 162, 1473-1482. http://dx.doi.org/10.1016/j apenergy.2015.03.140.

Martinek, J., Bingham, C., Weimer, A.W., 2012a. Computational modeling and onsun model validation for a multiple tube solar reactor with specularly reflective cavity walls. Part 1: heat transfer model. Chem. Eng. Sci. 81, 298-310. http://dx. doi.org/10.1016/j.ces.2012.06.064.

Martinek, J., Bingham, C., Weimer, A.W., 2012b. Computational modeling of a multiple tube solar reactor with specularly reflective cavity walls. Part 2: steam gasification of carbon. Chem. Eng. Sci. 81, 285-297. http://dx.doi.org/10.1016/j. ces.2012.06.065.

Martinek, J., Viger, R., Weimer, A.W., 2014. Transient simulation of a tubular packed bed solar receiver for hydrogen generation via metal oxide thermochemica cycles. Sol. Energy 105, 613-631. http://dx.doi.org/10.1016 j.solener.2014.04.022.

Martinek, J., Weimer, A.W., 2013a. Design considerations for a multiple tube solar reactor. Sol. Energy 90, 68-83. http://dx.doi.org/10.1016/j.solener.2013.01.004.

Martinek, J., Weimer, A.W., 2013b. Evaluation of finite volume solutions for radiative heat transfer in a closed cavity solar receiver for high temperature solar thermal processes. Int. J. Heat Mass Transf. 58, 585-596. http://dx.doi.org/ 10.1016/j.ijheatmasstransfer.2012.11.065.

McDaniel, A.H., Ambrosini, A., Coker, E.N., Miller, J.E., Chueh, W.C., O’Hayre, R., Tong, J., 2014. Nonstoichiometric perovskite oxides for solar thermochemical $\mathrm{H}_{2}$ and CO production. Energy Proc. 49, 2009-2018. http://dx.doi.org/10.1016 j.egypro.2014.03.213.

McDaniel, A.H., 2017. Renewable energy carriers derived from concentrating solar power and nonstoichiometric oxides. Curr. Opin. Green Sustain. Chem. http:// dx.doi.org/10.1016/j.cogsc.2017.02.004.

Melchior, T., Perkins, C., Lichty, P., Weimer, A.W., Steinfeld, A., 2009. Solar-driven biochar gasification in a particle-flow reactor. Chem. Eng. Process. 48, 12791287. http://dx.doi.org/10.1016/j.cep.2009.05.006.

Melchior, T., Perkins, C., Weimer, A.W., Steinfeld, A., 2008. A cavity-receiver containing a tubular absorber for high-temperature thermochemical processing using concentrated solar energy. Int. J. Therm. Sci. 47, 1496-1503. http://dx.doi. org/10.1016/j.ijthermalsci.2007.12.003.

Michalsky, R., Botu, V., Hargus, C.M., Peterson, A.A., Steinfeld, A., 2015a. Design principles for metal oxide redox materials for solar-driven isothermal fue production. Adv. Energy Mater. 5, 1401082. http://dx.doi.org/10.1002/ aenm.201401082.

Michalsky, R., Pfromm, P.H., Steinfeld, A., 2015. Rational design of metal nitride redox materials for solar-driven ammonia synthesis 5 . http://dx.doi.org/10 1098/rsfs.2014.0084. 
Miller, J.E., Allendorf, M.D., Diver, R.B., Evans, L.R., Siegel, N.P., Stuecker, J.N., 2008. Metal oxide composites and structures for ultra-high temperature solar thermochemical cycles. J. Mater. Sci. 43, 4714-4728.

Miller, J.E., Ambrosini, A., Coker, E.N., Allendorf, M., McDaniel, A., 2014a. Advancing oxide materials for thermochemical production of solar fuels. Energy Proc. 49, 2019-2026.

Miller, J.E., McDaniel, A.H., Allendorf, M.D., 2014b. Considerations in the design of materials for solar-driven fuel production using metal-oxide thermochemical cycles. Adv. Energy Mater. 4, 1300469. http://dx.doi.org/10.1002 aenm.201300469.

Mishchenko, M.I., 2010. Poynting-Stokes tensor and radiative transfer in discrete random media: the microphysical paradigm. Opt. Express 18, 19770-19791. http://dx.doi.org/10.1364/OE.18.019770.

Modest, M.F., 2013. Radiative Heat Transfer. Third ed. Academic Press, San Diego.

Möller, S., Palumbo, R., 2001. Solar thermal decomposition kinetics of ZnO in the temperature range 1950-2400K. Chem. Eng. Sci. 56 (15), 4505-4515.

Muhich, C.L., Aston, V.J., Trottier, R.M., Weimer, A.W., Musgrave, C.B., 2015a. Firstprinciples analysis of cation diffusion in mixed metal ferrite spinels. Chem. Mater. 28, 214-226.

Muhich, C.L., Aston, V.J., Trottier, R.M., Weimer, A.W., Musgrave, C.B., 2016a. Firstprinciples analysis of cation diffusion in mixed metal ferrite spinels. Chem. Mater. 28, 214-226.

Muhich, C.L., Ehrhart, B.D., Al-Shankiti, I., Ward, B.J., Musgrave, C.B., Weimer, A W., 2016b. A review and perspective of efficient hydrogen generation via solar thermal water splitting. Wiley Interdiscipl. Rev.: Energy Environ. 5, 261-287.

Muhich, C.L., Ehrhart, B.D., Witte, V.A., Miller, S.L., Coker, E.N., Musgrave, C.B. Weimer, A.W., 2015b. Predicting the solar thermochemical water splitting ability and reaction mechanism of metal oxides: a case study of the hercynite family of water splitting cycles. Energy Environ. Sci. 8, 3687-3699.

Muhich, C.L., Weston, K.C., Arifin, D., McDaniel, A.H., Musgrave, C.B., Weimer, A.W. 2015c. Extracting kinetic information from complex gas-solid reaction data. Ind. Eng. Chem. Res. 54, 4113-4122.

Muhich, C.L., Evanko, B.W., Weston, K.C., Lichty, P., Liang, X., Martinek, J., Musgrave C.B., Weimer, A.W., 2013. Efficient generation of $\mathrm{H}_{2}$ by splitting water with an isothermal redox cycle. Science 341 (6145), 540-542.

Muthusamy, J.P., Calvet, N., Shamim, T., 2014. Numerical investigation of a metaloxide reduction reactor for thermochemical energy storage and solar fue production. Energy Proc. 61, 2054-2057. http://dx.doi.org/10.1016/ j.egypro.2014.12.074.

Müller, R., Lipiński, W., Steinfeld, A., 2008. Transient heat transfer in a directlyirradiated solar chemical reactor for the thermal dissociation of $\mathrm{ZnO}$. Appl. Therm. Eng. 28, 524-531. http://dx.doi.org/10.1016/j. applthermaleng.2007.05.002.

Nakamura, T., 1977. Hydrogen production from water utilizing solar heat at high temperatures. Sol. Energy 19, 467-475. http://dx.doi.org/10.1016/0038-092X (77)90102-5.

Neises, M., Tescari, S., de Oliveira, L., Roeb, M., Sattler, C., Wong, B., 2012. Solarheated rotary kiln for thermochemical energy storage. Sol. Energy 86, 3040 3048. http://dx.doi.org/10.1016/j.solener.2012.07.012.

Oles, A.S., Jackson, G.S., 2015. Modeling of a concentrated-solar, falling-particle receiver for ceria reduction. Sol. Energy 122, 126-147. http://dx.doi.org/ 10.1016/j.solener.2015.08.009.

Perkins, C., Lichty, P., Weimer, A.W., 2007. Determination of aerosol kinetics of thermal ZnO dissociation by thermogravimetry. Chem. Eng. Sci. 62, 5952-5962. http://dx.doi.org/10.1016/j.ces.2007.06.039.

Perkins, C., Weimer, A., 2007. Computational fluid dynamics simulation of a tubular aerosol reactor for solar thermal $\mathrm{ZnO}$ decomposition. J. Sol. Energy Eng. 129, 391-404. http://dx.doi.org/10.1115/1.2769700.

Perkins, C., Weimer, A.W., 2004. Likely near-term solar-thermal water splitting technologies. Int. J. Hydrogen Energy 29, 1587-1599. http://dx.doi.org/10.1016/ j.ijhydene.2004.02.019.

Petrasch, J., Haussener, S., Lipiński, W., 2011. Discrete vs. continuum-scale simulation of radiative transfer in semitransparent two-phase media. J. Quant. Spectrosc. Radiat. Transfer 112, 1450-1459. http://dx.doi.org/10.1016/ j.jqsit.2011.01.025.

Petrasch, J., Meier, F., Friess, H., Steinfeld, A., 2008a. Tomography based determination of permeability, Dupuit-Forchheimer coefficient, and interfacial heat transfer coefficient in reticulate porous ceramics. Int. J. Heat Fluid Flow 29, 315-326. http://dx.doi.org/10.1016/j.ijheatfluidflow.2007.09.001.

Petrasch, J., Schrader, B., Wyss, P., Steinfeld, A., 2008b. Tomography-based determination of the effective thermal conductivity of fluid-saturated reticulate porous ceramics. J. Heat Transfer 130. http://dx.doi.org/10.1115/ 1.2804932. 032602-032602.

Petrasch, J., Wyss, P., Stämpfli, R., Steinfeld, A., 2008c. Tomography-based multiscale analyses of the 3D geometrical morphology of reticulated porous ceramics. J. Am. Ceram. Soc. 91, 2659-2665. http://dx.doi.org/10.1111/j.15512916.2008.02308.x.

Petrasch, J., Wyss, P., Steinfeld, A., 2007. Tomography-based Monte Carlo determination of radiative properties of reticulate porous ceramics. J. Quant Spectrosc. Radiat. Transfer 105, 180-197. http://dx.doi.org/10.1016/j. jqsit.2006.11.002.

Piatkowski, N., Steinfeld, A., 2008. Solar-driven coal gasification in a thermally irradiated packed-bed reactor. Energy Fuels 22, 2043-2052. http://dx.doi.org/ 10.1021/ef800027c.
Randrianalisoa, J., Lipiński, W., 2014. Effect of pore-level geometry on far-field radiative properties of three-dimensionally ordered macroporous ceria particle. Appl. Opt. 53, 1290-1297. http://dx.doi.org/10.1364/A0.53.001290.

Romero, M., Steinfeld, A., 2012. Concentrating solar thermal power and thermochemical fuels. Energy Environ. Sci. 5, 9234-9245. http://dx.doi.org/ 10.1039/C2EE21275G.

Rydén, M., Lyngfelt, A., Mattisson, T., 2011. Combined manganese/iron oxides as oxygen carrier for chemical looping combustion with oxygen uncoupling (CLOU) in a circulating fluidized bed reactor system. Energy Proc. 4, 341-348.

Saade, E., Bingham, C., Clough, D.E., Weimer, A.W., 2012. Dynamics of a solarthermal transport-tube reactor. Chem. Eng. J. 213, 272-285. http://dx.doi.org/ 10.1016/j.cej.2012.09.117.

Saggio-Woyansky, J., Scott, C.E., Minnear, W.P., 1992. Processing of porous ceramics. Am. Ceram. Soc. Bull. 71 (11), 1674-1682.

Scheffe, J.R., Li, J., Weimer, A.W., 2010. A spinel ferrite/hercynite water-splitting redox cycle. Int. J. Hydrogen Energy 35, 3333-3340. http://dx.doi.org/10.1016/j. ijhydene.2010.01.140.

Scheffe, J.R., McDaniel, A.H., Allendorf, M.D., Weimer, A.W., 2013a. Kinetics and mechanism of solar-thermochemical $\mathrm{H}_{2}$ production by oxidation of a cobalt ferrite-zirconia composite. Energy Environ. Sci. 6, 963-973. http://dx.doi.org/ 10.1039/C3EE23568H.

Scheffe, J.R., Weibel, D., Steinfeld, A., 2013b. Lanthanum-strontium-manganese perovskites as redox materials for solar thermochemical splitting of $\mathrm{H}_{2} \mathrm{O}$ and $\mathrm{CO}_{2}$. Energy Fuels 27, 4250-4257.

Schunk, L.O., Lipiński, W., Steinfeld, A., 2009a. Heat transfer model of a solar receiver-reactor for the thermal dissociation of $\mathrm{ZnO}$-experimental validation at $10 \mathrm{~kW}$ and scale-up to $1 \mathrm{MW}$. Chem. Eng. J. 150, 502-508. http://dx.doi.org/ 10.1016/j.cej.2009.03.012

Schunk, L.O., Lipiński, W., Steinfeld, A., 2009b. Ablative heat transfer in a shrinking packed-bed of $\mathrm{ZnO}$ undergoing solar thermal dissociation. AIChE J. 55, 16591666. http://dx.doi.org/10.1002/aic.11782.

Schunk, L.O., Steinfeld, A., 2009. Kinetics of the thermal dissociation of ZnO exposed to concentrated solar irradiation using a solar-driven thermogravimeter in the 1800-2100 K range. AIChE J. 55, 1497-1504. http://dx.doi.org/10.1002/ aic. 11765 .

Stamatiou, A., Loutzenhiser, P.G., Steinfeld, A., 2010. Solar syngas production via $\mathrm{H}_{2} \mathrm{O} / \mathrm{CO}_{2}$-splitting thermochemical cycles with $\mathrm{Zn} / \mathrm{ZnO}$ and $\mathrm{FeO} / \mathrm{Fe}_{3} \mathrm{O}_{4}$ redox reactions. Chem. Mater. 22, 851-859. http://dx.doi.org/10.1021/cm9016529.

Stan, M., Zhu, Y.T., Jiang, H., Butt, D.P., 2004. Kinetics of oxygen removal from ceria. J. Appl. Phys. 95, 3358-3361. http://dx.doi.org/10.1063/1.1650890.

Steinfeld, A., 2005. Solar thermochemical production of hydrogen--a review. Sol Energy 78, 603-615.

Steinfeld, A., Sanders, S., Palumbo, R., 1999. Design aspects of solar thermochemical engineering-a case study: Two-step water-splitting cycle using the $\mathrm{Fe}_{3} \mathrm{O}_{4} / \mathrm{FeO}$ redox system. Sol. Energy 65, 43-53. http://dx.doi.org/10.1016/S0038-092X(98) 00092-9.

Ströhle, S., Haselbacher, A., Jovanovic, Z.R., Steinfeld, A., 2014. Transient discretegranule packed-bed reactor model for thermochemical energy storage. Chem. Eng. Sci. 117, 465-478. http://dx.doi.org/10.1016/j.ces.2014.07.009.

Suter, S., Haussener, S., 2013. Morphology engineering of porous media for enhanced solar fuel and power production. JOM 65 (12), 1702-1709.

Suter, S., Steinfeld, A., Haussener, S., 2014. Pore-level engineering of macroporous media for increased performance of solar-driven thermochemical fuel processing. Int. J. Heat Mass Transf. 78, 688-698. http://dx.doi.org/10.1016/j. ijheatmasstransfer.2014.07.020.

Tamaura, Y., Kojima, M., Sano, T., Ueda, Y., Hasegawa, N., Tsuji, M., 1998. Thermodynamic evaluation of water splitting by a cation-excessive (Ni, Mn) ferrite. Int. J. Hydrogen Energy 23, 1185-1191.

Vafai, K., Tien, C., 1981. Boundary and inertia effects on flow and heat transfer in porous media. Int. J. Heat Mass Transf. 24, 195-203. http://dx.doi.org/10.1016/ 0017-9310(81)90027-2.

Villafán-Vidales, H.I., Abanades, S., Arancibia-Bulnes, C.A., Riveros-Rosas, D., Romero-Paredes, H., Espinosa-Paredes, G., Estrada, C.A., 2012. Radiative heat transfer analysis of a directly irradiated cavity-type solar thermochemical reactor by Monte-Carlo ray tracing. J. Renew. Sustain. Energy 4, 043125. http:// dx.doi.org/10.1063/1.4747825.

Villafán-Vidales, H.I., Abanades, S., Caliot, C., Romero-Paredes, H., 2011. Heat transfer simulation in a thermochemical solar reactor based on a volumetric porous receiver. Appl. Therm. Eng. 31, 3377-3386. http://dx.doi.org/10.1016/j. applthermaleng.2011.06.022

Villafán-Vidales, H.I., Abanades, S., Montiel-González, M., Romero-Paredes, H. Arancibia-Bulnes, C.A., Estrada, C.A., 2015. Transient heat transfer simulation of a $1 \mathrm{~kW}_{\text {th }}$ moving front solar thermochemical reactor for thermal dissociation of compressed ZnO. Chem. Eng. Res. Des. 93, 174-184. http://dx.doi.org/10.1016/j. cherd.2014.05.027.

Viskanta, R., Mengüç, M., 1987. Radiation heat transfer in combustion systems. Prog. Energy Combust. Sci. 13, 97-160. http://dx.doi.org/10.1016/0360-1285 (87)90008-6.

Vyazovkin, S., 1997. Advanced isoconversional method. J. Therm. Anal. 49, 14931499.

Vyazovkin, S., Lesnikovich, A., 1988. Estimation of the pre-exponential factor in the isoconversional calculation of effective kinetic parameters. Thermochim. Acta 128, 297-300.

Vyazovkin, S., Wight, C.A., 1999. Model-free and model-fitting approaches to kinetic analysis of isothermal and nonisothermal data. Thermochim. Acta 340, 53-68. 
Wang, F., Shuai, Y., Wang, Z., Leng, Y., Tan, H., 2014a. Thermal and chemical reaction performance analyses of steam methane reforming in porous media solar thermochemical reactor. Int. J. Hydrogen Energy 39, 718-730. http://dx.doi.org/ 10.1016/j.ijhydene.2013.10.132.

Wang, F., Tan, J., Shuai, Y., Gong, L., Tan, H., 2014b. Numerical analysis of hydrogen production via methane steam reforming in porous media solar thermochemical reactor using concentrated solar irradiation as heat source. Energy Convers. Manage. 87, 956-964. http://dx.doi.org/10.1016/j. enconman.2014.08.003.

Wheeler, V.M., Randrianalisoa, J., Tamma, K., Lipiński, W., 2014. Spectral radiative properties of three-dimensionally ordered macroporous ceria particles. J. Quant. Spectrosc. Radiat. Transfer 143, 63-72. http://dx.doi.org/10.1016/j. jqsit.2013.08.007.

Whitaker, S., 1999. The method of volume averaging, theory and applications of transport in porous media. Kluwer Academic, Dorderecht.

Yang, J., Wang, L., Tong, L., Li, H., 2004. Modeling of radiative heat transfer between high-temperature fluidized beds and immersed walls. Chem. Eng. Sci. 59, 31953199. http://dx.doi.org/10.1016/j.ces.2004.03.032.

Yue, L., Lipiński, W., 2015a. A numerical model of transient thermal transport phenomena in a high-temperature solid-gas reacting system for $\mathrm{CO}_{2}$ capture applications. Int. J. Heat Mass Transf. 85, 1058-1068. http://dx.doi.org/10.1016/ j.ijheatmasstransfer.2015.01.124.
Yue, L., Lipiński, W., 2015b. Effect of surface radiative properties of a $\mathrm{CO}_{2}$ sorbent particle on its interactions with high-flux solar irradiation. Opt. Express 23, A752-A763. http://dx.doi.org/10.1364/OE.23.00A752.

Yue, L., Lipiński, W., 2015c. Thermal transport model of a sorbent particle undergoing calcination-carbonation cycling. AIChE J. 61, 2647-2656. http:// dx.doi.org/10.1002/aic.14840.

von Zedtwitz, P., Steinfeld, A., 2005. Steam-gasification of coal in a fluidizedbed/packed-bed reactor exposed to concentrated thermal radiation modeling and experimental validation. Ind. Eng. Chem. Res. 44, 3852-3861. http://dx.doi. org/10.1021/ie050138w.

von Zedtwitz, P., Lipiński, W., Steinfeld, A., 2007. Numerical and experimental study of gas-particle radiative heat exchange in a fluidized-bed reactor for steamgasification of coal. Chem. Eng. Sci. 62, 599-607. http://dx.doi.org/10.1016/j. ces.2006.09.027.

Z'Graggen, A., Steinfeld, A., 2008. A two-phase reactor model for the steamgasification of carbonaceous materials under concentrated thermal radiation. Chem. Eng. Process. 47, 655-662. http://dx.doi.org/10.1016/j.cep.2006.12.003.

Z'Graggen, A., Steinfeld, A., 2009. Heat and mass transfer analysis of a suspension of reacting particles subjected to concentrated solar radiation - application to the steam-gasification of carbonaceous materials. Int. J. Heat Mass Transf. 52, 385395. http://dx.doi.org/10.1016/j.ijheatmasstransfer.2008.05.023. 